University of Montana

ScholarWorks at University of Montana

Numerical Terradynamic Simulation Group

Publications

Numerical Terradynamic Simulation Group

8-2011

\title{
Evaluation of MERRA Land Surface Estimates in Preparation for the Soil Moisture Active Passive Mission
}

Yonghong Yi

University of Montana - Missoula

John S. Kimball

University of Montana - Missoula

Lucas A. Jones

Rolf H. Reichle

NASA

Kyle C. McDonald

City College of New York

Follow this and additional works at: https://scholarworks.umt.edu/ntsg_pubs

Let us know how access to this document benefits you.

\section{Recommended Citation}

Yi, Y., J. Kimball, L. Jones, R. Reichle, and K. McDonald, 2011: Evaluation of MERRA Land Surface Estimates in Preparation for the Soil Moisture Active Passive Mission. J. Climate, 24, 3797-3816, doi: 10.1175/2011JCLI4034.1

This Article is brought to you for free and open access by the Numerical Terradynamic Simulation Group at ScholarWorks at University of Montana. It has been accepted for inclusion in Numerical Terradynamic Simulation Group Publications by an authorized administrator of ScholarWorks at University of Montana. For more information, please contact scholarworks@mso.umt.edu. 


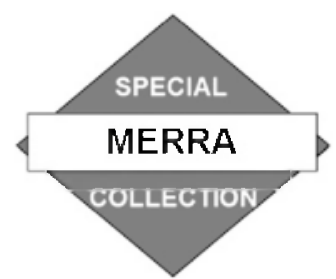

\title{
Evaluation of MERRA Land Surface Estimates in Preparation for the Soil Moisture Active Passive Mission
}

\author{
YONGHONG YI, JOHN S. KIMBALL, AND LUCAS A. JONES \\ Flathead Lake Biological Station, The University of Montana, Polson, and Numerical Terradynamic Simulation Group, \\ The University of Montana, Missoula, Montana \\ ROLF H. REICHLE \\ Global Modeling and Assimilation Office, NASA Goddard Space Flight Center, Greenbelt, Maryland
}

\author{
KYLE C. MCDONALD
}

Jet Propulsion Laboratory, California Institute of Technology, Pasadena, California

(Manuscript received 26 August 2010, in final form 3 February 2011)

\begin{abstract}
The authors evaluated several land surface variables from the Modern-Era Retrospective Analysis for Research and Applications (MERRA) product that are important for global ecological and hydrological studies, including daily maximum $\left(T_{\max }\right)$ and minimum $\left(T_{\min }\right)$ surface air temperatures, atmosphere vapor pressure deficit (VPD), incident solar radiation $\left(\mathrm{SW}_{\mathrm{rad}}\right)$, and surface soil moisture. The MERRA results were evaluated against in situ measurements, similar global products derived from satellite microwave [the Advanced Microwave Scanning Radiometer for Earth Observing System (EOS) (AMSR-E)] remote sensing and earlier generation atmospheric analysis [Goddard Earth Observing System version 4 (GEOS-4)] products. Relative to GEOS-4, MERRA is generally warmer $\left(\sim 0.5^{\circ} \mathrm{C}\right.$ for $T_{\min }$ and $\left.T_{\max }\right)$ and drier $(\sim 50$ Pa for VPD) for low- and middle-latitude regions $\left(\angle 50^{\circ} \mathrm{N}\right)$ associated with reduced cloudiness and increased $\mathrm{SW}_{\mathrm{rad}}$. MERRA and AMSR-E temperatures show relatively large differences $\left(>3^{\circ} \mathrm{C}\right)$ in mountainous areas, tropical forest, and desert regions. Surface soil moisture estimates from MERRA (0-2-cm depth) and two AMSR-E products $(\sim 0-1-\mathrm{cm}$ depth) are moderately correlated $(R \sim 0.4)$ for middle-latitude regions with low to moderate vegetation biomass. The MERRA derived surface soil moisture also corresponds favorably with in situ observations $(R=0.53 \pm 0.01, p<0.001)$ in the midlatitudes, where its accuracy is directly proportional to the quality of MERRA precipitation. In the high latitudes, MERRA shows inconsistent soil moisture seasonal dynamics relative to in situ observations. The study's results suggest that satellite microwave remote sensing may contribute to improved reanalysis accuracy where surface meteorological observations are sparse and in cold land regions subject to seasonal freeze-thaw transitions. The upcoming NASA Soil Moisture Active Passive (SMAP) mission is expected to improve MERRA-type reanalysis accuracy by providing accurate global mapping of freeze-thaw state and surface soil moisture with 2-3-day temporal fidelity and enhanced $(\leq 9 \mathrm{~km})$ spatial resolution.
\end{abstract}

\section{Introduction}

Errors in surface meteorological forcing data account for a significant portion of the uncertainty in ecosystem and hydrologic model simulations, particularly in regions

Corresponding author address: Yonghong Yi, Flathead Lake Biological Station, The University of Montana, 32135 Biostation Lane, Polson, MT 59860-9569.

E-mail: yonghong.yi@ntsg.umt.edu of the globe with sparse surface observation networks (Zhao et al. 2006; Mu et al. 2009; Zhang et al. 2009). These modeling efforts commonly utilize surface meteorological drivers obtained from satellite remote sensing, global climate model outputs, or hybrid products (e.g., global atmospheric data assimilation systems, including reanalysis products) to define biophysical attributes and water, mass, and energy exchanges (e.g., Running et al. 2004; Randerson et al. 2009). 
Although atmospheric (re)analysis products combine numerical modeling of atmospheric processes with conventional and satellite observations through data assimilation, uncertainty remains in several variables of interest for application in ecosystem and hydrological models (Berg et al. 2003; Sheffield et al. 2006; Zhao et al. 2006). Incident solar radiation drives the surface energy budget, land surface evaporation, and photosynthetic uptake of $\mathrm{CO}_{2}$, whereas temperature and moisture availability determine rates of evapotranspiration, photosynthesis, and ecosystem respiration (Churkina et al. 1999; Running et al. 2004). The diurnal range of surface air temperature is closely related to surface energy partitioning, surface moisture status, and atmospheric humidity (Kimball et al. 1997), while surface air humidity determines atmospheric evaporative demand and cues stomatal regulation of canopy evaporative resistance (Running et al. 2004; Jolly et al. 2005). Significant uncertainties have been reported in global reanalysis products of shortwave radiation that are connected to the various cloudmodeling schemes used in the reanalysis systems (e.g., Betts et al. 2006). Because of the typically coarse spatial resolution, reanalysis temperature fields can also be significantly biased over complex and heterogeneous terrain and locations with persistent cloud cover. Reanalysis soil moisture (SM) is highly dependent on the underlying model parameterization and can vary significantly for different model-based products (Dirmeyer et al. 2004; Li et al. 2005).

The National Aeronautics and Space Administration (NASA) Global Modeling and Assimilation Office (GMAO) most recent reanalysis product, the ModernEra Retrospective Analysis for Research and Applications (MERRA), is based on an updated modeling and assimilation system that ingests data from many modern observing systems and is expected to show advances in representing meteorological and hydrological processes over existing reanalyses (Rienecker et al. 2008). MERRA is currently being used as a surrogate for the development of future Level 4 (L4) soil moisture and carbon products to be generated by the NASA Soil Moisture Active Passive (SMAP) mission (Entekhabi et al. 2010). The SMAP mission will provide global measurements of surface soil moisture and freeze-thaw status, with improved $(<10 \mathrm{~km})$ resolution over current satellite microwave remote sensing products available from the Special Sensor Microwave Imager (SSM/I), Earth Observing System (EOS) Advanced Microwave Scanning Radiometer (AMSR-E), and the Soil Moisture and Ocean Salinity (SMOS) mission. In the Level 4 soil moisture algorithm, SMAP observations will be assimilated within a land surface data assimilation system that is being developed in the Goddard Earth Observing
System version 5 (GEOS-5) framework and thus shares many components with MERRA, including the basic structure of the land surface model. After launch, the GEOS system will provide major meteorological inputs for the generation of SMAP Level 4 soil moisture and carbon products, including surface air temperatures, incident solar radiation, humidity, and land surface parameters. Prior to launch, the SMAP Level 4 soil moisture and carbon algorithms are being developed and tested under the GEOS system to determine the additional value provided by SMAP observations over existing systems for understanding ecosystem and hydrologicalprocesses (J. S. Kimball et al. 2010, unpublished manuscript; Reichle et al. 2011).

As a first step toward the development of the SMAP Level 4 products, this study compares selected daily land surface parameters important for hydro-ecological modeling from MERRA with similar variables from the earlier generation GEOS-4 analysis, satellite passive microwave (AMSR-E) remote sensing retrievals, and in situ measurements distributed around the globe. The objectives of this study were to 1 ) evaluate the uncertainty and relative accuracy of MERRA against in situ observations and the previous GEOS-4 analysis for selected land surface meteorological variables, and 2) examine relationships and accuracy differences between MERRA estimates and independent satellite microwave remote sensing products to clarify the potential value of the satellite observations for model assimilation and improvement of the analysis products. The variables examined in this study include daily incident solar radiation $\left(\mathrm{SW}_{\mathrm{rad}}\right)$, maximum $\left(T_{\max }\right)$ and minimum $\left(T_{\min }\right)$ air temperatures, and vapor pressure deficit (VPD) at $\sim 2$-m screen-level height, and surface soil moisture (0-2-cm depth). Precipitation, although one of the most important drivers of hydrological processes, is addressed by Reichle et al. (2011) and Bosilovich et al. (2011) and is not explicitly addressed in this paper. This study focuses on global land areas with additional emphasis on northern high-latitude regions $\left(>45^{\circ} \mathrm{N}\right)$, where terrestrial carbon, water, and energy fluxes provide potentially important climate feedbacks and modeling efforts rely heavily on global reanalysis data.

\section{Data}

The datasets and in situ observations used for evaluation and validation of the MERRA land parameters in this study are summarized in Table 1 . We evaluated GEOS-4 and MERRA surface meteorological data against AMSR-E [University of Montana (UM)] daily air temperature retrievals and daily observations from the global World Meteorological Organization (WMO) 
TABLE 1. Summary of evaluated datasets and in situ observations used for validation.

\begin{tabular}{lllccc}
\hline \hline \multicolumn{1}{c}{ Datasets } & Properties & \multicolumn{1}{c}{ Evaluated variables } & Evaluated period & Temporal resolution & Spatial resolution \\
\hline GEOS-4 & Analysis & $T_{\min }, T_{\max }, \mathrm{VPD}, \mathrm{SW}_{\mathrm{rad}}$ & $2000-06$ & 3 -hourly & $1^{\circ} \times 1.25^{\circ}$ \\
MERRA & Reanalysis & $T_{\min }, T_{\max }, \mathrm{VPD}, \mathrm{SW}_{\mathrm{rad}}, \mathrm{SM}$ & $2000-06$ & hourly & $1^{\circ} \times 2 / 3^{\circ}$ \\
GEWEX-SRB & Model & $\mathrm{SW}_{\mathrm{rad}}$ & $2000-06$ & Daily & $25 \mathrm{~km}$ \\
AMSR-E UM & Satellite & $T_{\min }, T_{\max }, \mathrm{SM}$ & $2003-06$ & $1-3$ day & $25 \mathrm{~km}$ \\
AMSR-E VU & Satellite & $\mathrm{SM}$ & $2003-06$ & $1-3$ day & Point \\
WMO & In situ & $T_{\min }, T_{\max }, \mathrm{VPD}$ & $2000-06$ & Daily & Point \\
CONUS SW & In situ & $\mathrm{SW}_{\text {rad }}$ & $2001-02$ & Daily & Point \\
FLUXNET & In situ & $\mathrm{SW}_{\text {rad }}, \mathrm{SM}$ & $2000-06$ & Daily & \\
\hline
\end{tabular}

weather station network (Fig. 1a); the WMO observations were also used to evaluate the accuracy of VPD from GEOS-4 and MERRA. The Global Energy and Water Cycle Experiment (GEWEX) surface radiation budget (SRB) dataset and daily observations from a variety of in situ stations (Fig. 1b) were employed to evaluate solar radiation from GEOS-4 and MERRA. Surface soil moisture observations from AmeriFlux tower network sites (Fig. 1b) were used to evaluate MERRA and two AMSR-E [UM and Vrijie Universiteit (VU)] surface soil moisture products. A brief introduction of the GEOS-4 and MERRA modeling system, and the AMSR-E land parameter retrieval algorithms, is presented in this section. The appendix provides additional descriptions of the datasets listed in Table 1 and further data processing information.

\section{a. GEOS-4 and MERRA}

In this section we provide a brief overview of the GEOS-4 and MERRA modeling and assimilation

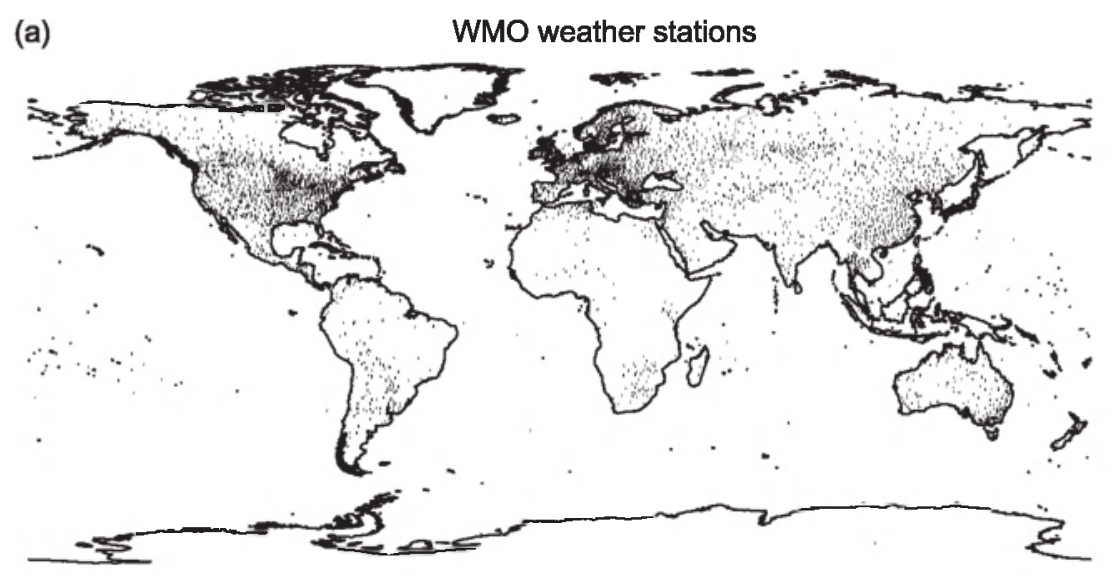

(b)

Weather stations (SWrad) and AmeriFlux tower sites

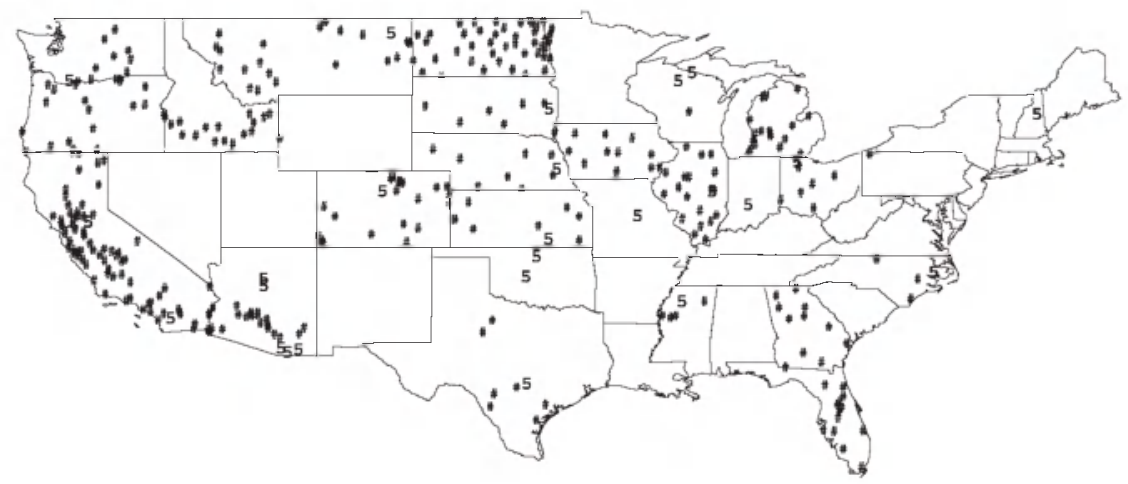

FIG. 1. (a) Location of NCDC WMO weather stations $(n>6000)$. (b) Contiguous U.S. locations of weather and agricultural stations with $\mathrm{SW}_{\mathrm{rad}}$ observations $(n=333$, solid triangles) and Ameriflux tower sites $\left(<50^{\circ} \mathrm{N} ; n=27\right.$, circles) with surface $(\leq 15 \mathrm{~cm})$ soil moisture observations. 
systems, while detailed descriptions of these systems are provided elsewhere (Bloom et al. 2005; Rienecker et al. 2008). GEOS-4 was the quasi-operational analysis system of the NASA GMAO (formerly Data Assimilation Office) from 2003 to 2006 (Bloom et al. 2005) and has been widely used for global assessment of climate trends and inputs for hydrological and ecological studies (Betts et al. 2003; Zhao et al. 2006; Mu et al. 2009). Up until 2006, the GEOS-4 analysis was used as the primary meteorological forcing for the NASA EOS Moderate Resolution Imaging Spectroradiometer (MODIS) MOD17 vegetation productivity algorithms (Zhao et al. 2006). The MOD17 algorithms are also being used with MERRA surface meteorology for development and testing of the SMAP L4 carbon algorithms (Kimball et al. 2009, 2010). Meteorological data from the GEOS-4.0.2 version were used for the current study.

MERRA is a 30 -yr reanalysis product generated by the GEOS-5.2.0 system (Rienecker et al. 2008; http:// gmao.gsfc.nasa.gov/research/merra/), and covering the modern satellite era from 1979 to the present. The GEOS-5 atmospheric general circulation model (AGCM) maintains the finite-volume dynamics from GEOS-4 but is also integrated with new packages, including the catchment land surface model designed to improve hydrological cycle studies (see below). The GEOS- 5 system was run at a horizontal resolution of $1 / 2^{\circ} \times 2 / 3^{\circ}$ (latitude $\times$ longitude) and 72 hybrid-sigma coordinate vertical levels to produce an observational analysis at 6-h intervals, while the GEOS- 4 system employs a $1^{\circ} \times 1.25^{\circ}$ horizontal resolution (latitude $\times$ longitude) with 55 vertical levels. The new GEOS-5 system incorporates information from many modern Earth observations, including SSM/I radiances, Atmospheric Infrared Sounder (AIRS) radiances and scatterometer-based wind retrievals, and is expected to improve over existing reanalysis products. Moreover, GEOS-5 primarily assimilates satellite raw radiance values using the Community Radiative Transfer Model (CRTM) rather than satellite retrievals employed by GEOS-4, except for single-level cloud motion vector winds, precipitation and surface wind speed, and column ozone estimates.

In GEOS-4, the data assimilation system was based on the Physical-Space Statistical Analysis System (PSAS) and an interactive system (iRET) was used for assimilating the Television and Infrared Observation Satellite (TIROS) Operational Vertical Sounder (TOVS) radiance data (Bloom et al. 2005). The new GEOS-5 system introduced the National Centers for Environmental Prediction (NCEP) Gridpoint Statistical Interpolation (GSI) scheme for the atmospheric assimilation to quantify differences between initial 6-hourly analysis fields and the background forecast model state. An increment analysis update (IAU) was also used to reduce periodic perturbations of the analysis at the forecast initialization.

The Community Land Model version 2 (CLM2) used in GEOS-4 is a traditional, layer-based model. The GEOS-5 catchment land surface model used in MERRA is designed to improve the treatment of land surface hydrological processes through explicit modeling of subgrid-scale soil moisture variability and its effect on runoff and evaporation (Koster et al. 2000). The basic computational unit of the model is the hydrological catchment (or watershed), with boundaries defined by topography. Within each element, the vertical profile of soil moisture is given by the equilibrium soil moisture profile and deviations from the equilibrium profile in a $0-2-\mathrm{cm}$ surface layer and $0-100-\mathrm{cm}$ "root zone" layer; the spatial variability of soil moisture is diagnosed from the bulk water prognostic variables and statistics of the catchment topography. The catchment model also includes a threelayer snow model that describes snow accumulation, melting, refreezing, and compaction in response to surface meteorological conditions (Stieglitz et al. 2001).

\section{b. Satellite microwave remote sensing algorithms}

Satellite passive microwave remote sensing provides an effective method for large-scale mapping of surface temperature and soil moisture patterns and is relatively insensitive to solar illumination, clouds, and atmospheric aerosol effects. The AMSR-E sensor onboard the polar orbiting NASA EOS Aqua satellite has $1: 30$ a.m./p.m. (descending/ascending orbit) equatorial crossings and has been providing global, multifrequency microwave radiometric brightness temperature $\left(T_{b}\right)$ measurements every 1-3 days since June of 2002. The AMSR-E sensor measures $H$ and $V$ polarization $T_{b}$ at six frequencies spanning 6.9-89.0 GHz. The two lower-frequency channels ( 6.9 and $10.7 \mathrm{GHz}$ ) are sensitive to changes in surface soil moisture (within $\sim 1-\mathrm{cm}$ soil depth), whereas higher frequency $(18.7,23.8$, and $36.5 \mathrm{GHz})$ channels are more suitable for surface temperature derivation owing to favorable $T_{b}$ correlation with surface temperature (Njoku et al. 2003; Jones et al. 2007).

Two AMSR-E land parameter products generated by the University of Montana (UM) and Vrijie Universiteit (VU) Amsterdam in collaboration with NASA were evaluated in this study. The UM products [available from the National Snow and Ice Data Center (NSIDC) at http://nsidc.org/data/nsidc-0451.html] use a simple radiative transfer model to derive daily $T_{\min }$ and $T_{\max }$ and surface soil moisture retrievals based on gridded AMSR-E $T_{b}$ data (Jones et al. 2009, 2010). The 18.7 and $23.8 \mathrm{GHz}$ frequencies are used to derive air temperatures, while surface soil moisture is derived separately 
using $T_{b}$ at 6.9 and $10.7 \mathrm{GHz}$. The radiative transfer model accounts for surface emissivity variations caused by vegetation roughness and inland and coastal open water bodies and also for vertically integrated atmospheric water vapor, except for cloud liquid water effects. Differences in local timing of AMSR-E air temperature retrievals at ascending and descending overpasses and the timing of $T_{\max }$ and $T_{\min }$ are also accounted for (Jones et al. 2010). The UM AMSR-E retrievals are provided over land under nonprecipitating and snow- and ice-free conditions.

The VU soil moisture products (http://geoservices. falw.vu.nl/) use the land surface parameter model radiative transfer scheme to simultaneously determine surface soil moisture and vegetation water content from AMSR-E brightness temperatures (Owe et al. 2008). The VU soil moisture algorithms use AMSR-E L2A swath $T_{b}$ inputs and surface soil moisture is derived from the 6.9- and 10.7-GHz frequencies. The UM and VU AMSR-E soil moisture algorithms differ in their solution for vegetation opacity, input temperature data, treatment of open water body effects, and detecting and screening of snow, frozen soils, and radio frequency inference (RFI). The UM algorithms consider the effects of subgrid scale open water variability on microwave emissivity and corresponding soil moisture retrievals, whereas the VU algorithms do not account for open water effects. The temperature retrievals are used to screen out frozen soil conditions in both algorithms (Owe et al. 2001; Jones et al. 2010), while an additional mask based on AMSR-E-derived land surface freeze-thaw state is also used in the UM algorithms.

Over dense vegetation, the ability of microwave remote sensing to detect surface soil moisture is limited. For both datasets (UM and VU), grid cells with 10.7-GHz frequency slant path vegetation optical depth (VOD) values greater than 1.2 were excluded from the analysis. The UM algorithm produces overall larger VOD values than the VU algorithm, with more stringent screening of frozen conditions, which results in fewer available retrievals in the UM product for most vegetated land areas, especially in boreal regions. Previous research has highlighted differences in soil moisture retrievals between AMSR-E descending and ascending overpasses in the VU product (Owe et al. 2008; Draper et al. 2009). However, mean diurnal differences in soil moisture retrievals between ascending and descending overpasses for the VU and UM products are relatively small compared to soil moisture variability over longer (e.g., monthly to seasonal) time scales. Therefore, retrievals from ascending and descending overpasses were combined on a gridcell-by-gridcell basis for each product to improve global daily coverage. Soil moisture retrievals

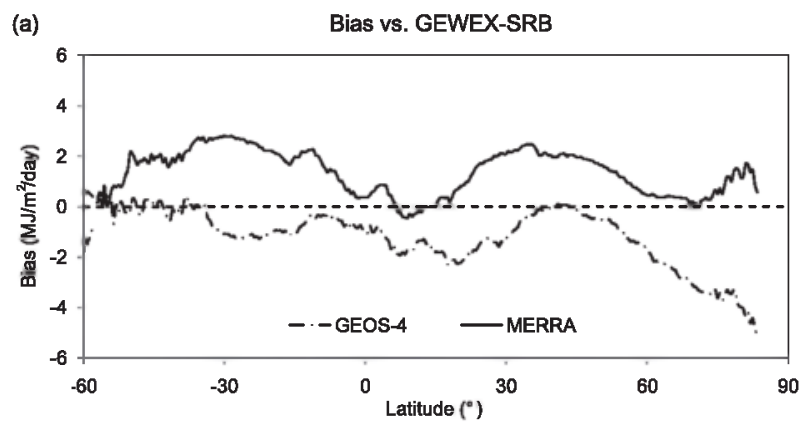

(b)

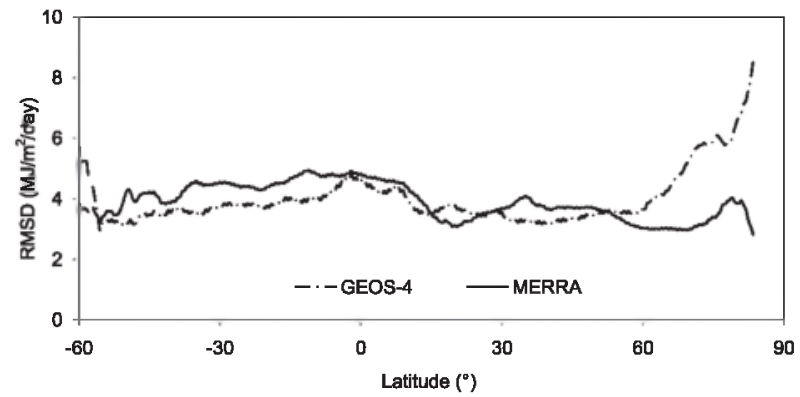

FIG. 2. Latitudinal distributions of (a) mean bias and (b) RMSD of GEOS-4 and MERRA vs GEWEX-SRB for 2000-06 daily $\mathrm{SW}_{\mathrm{rad}}$.

at $6.9-\mathrm{GHz}$ frequency were used exclusively except where strong 6.9-GHz RFI was detected (Njoku et al. 2005); these areas included the contiguous United States (CONUS), Japan, and some areas in the Middle East and India, whereby soil moisture retrievals at $10.7-\mathrm{GHz}$ frequency were used instead.

\section{Results}

In this section we summarize our results by variable type. Within each subsection, we first compare the relevant global data products (i.e., MERRA, GEOS-4, and AMSR-E), followed by the validation against in situ observations.

\section{a. Incident solar radiation}

The latitudinal distributions of mean difference and root-mean-square difference (RMSD) values between MERRA-GEOS-4 and GEWEX-SRB SW rad $_{\text {daily es- }}$ timates are presented in Fig. 2, while the global patterns of these differences are shown in Figs. 3a-b. MERRA generally overestimates $\mathrm{SW}_{\text {rad }}$ relative to the GEWEXSRB, especially in the middle latitudes of both global hemispheres, with the largest differences occurring in South America and the Tibetan Plateau $\left(>3 \mathrm{MJ} \mathrm{m}^{-2}\right.$ day $\left.^{-1}\right)$. However, additional uncertainty in the satellite solar radiation products in complex terrain may contribute to the above differences. For example, previous research 
(a)

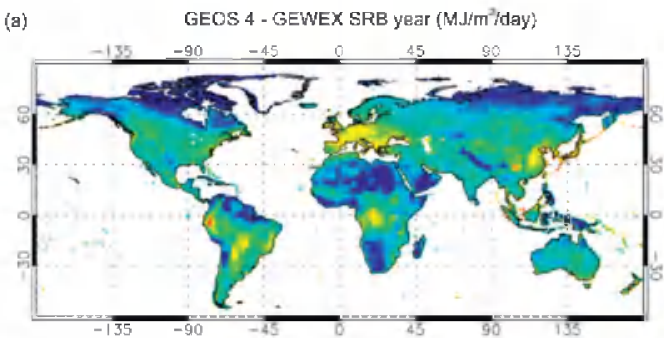

(c)
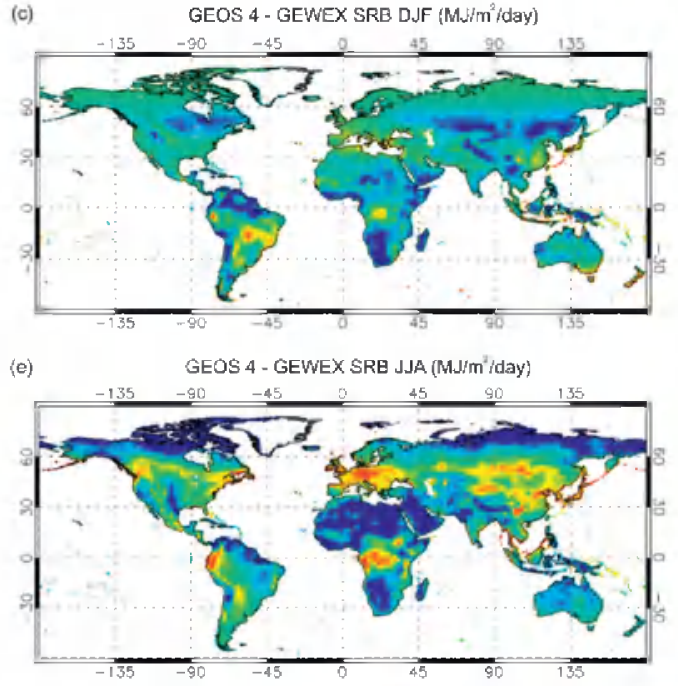

(b)

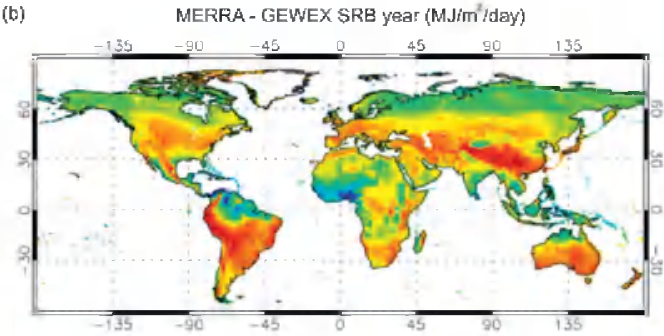

(d)

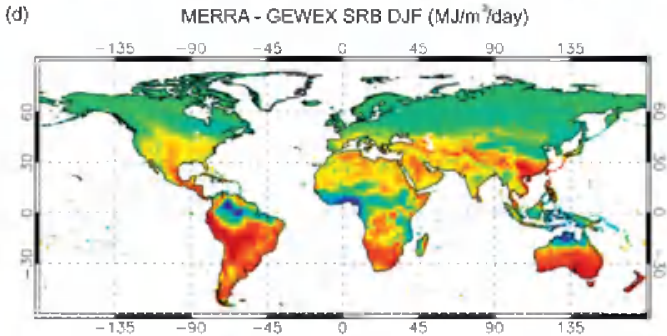

(f)

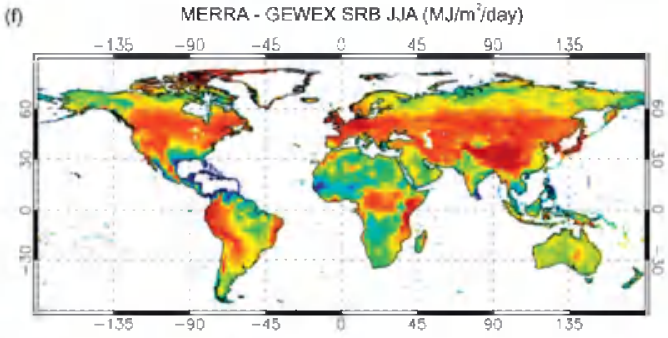

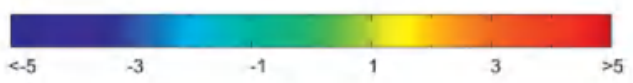

FIG. 3. (a),(b) Annual and (c)-(f) seasonal bias of (left) GEOS-4 and (right) MERRA vs GEWEX-SRB for 2000-06 daily $S W_{\text {rad }}(\mathrm{DJF}=$ December to February, JJA = June to August).

has shown that the GEWEX-SRB underestimates $\mathrm{SW}_{\mathrm{rad}}\left(\sim 1.5 \mathrm{MJ} \mathrm{m}^{-2} \mathrm{day}^{-1}\right)$ over the Tibetan Plateau (Yang et al. 2008); the $\mathrm{SW}_{\text {rad }}$ differences in Fig. 3 are compounded by positive MERRA bias and negative GEWEX-SRB bias over these highland areas. The MERRA $\mathrm{SW}_{\text {rad }}$ estimates also show a small negative discrepancy in the tropics, mainly over northeastern Amazonia, portions of northern Africa, and tropical western Pacific regions. In contrast, the GEOS-4 product generally underestimates $S W_{\text {rad }}$ relative to the GEWEX-SRB, with maximum differences in excess of $3 \mathrm{MJ} \mathrm{m}^{-2}$ day $^{-1}$ in the high northern latitudes $\left(>60^{\circ} \mathrm{N}\right)$ and northern tropical deserts. The MERRA SW rad $_{\text {estimates show similar or }}$ slightly larger RMSD values (relative to the GEWEX$\mathrm{SRB}$ ) than the GEOS-4 product over most latitudes, although the GEOS-4 SW rad results show a marked increase in RMSD values above approximately $60^{\circ} \mathrm{N}$ (Fig. 2b).

The differences between MERRA-GEOS-4 and GEWEX-SRB daily SW rad estimates also show very different seasonal patterns (Figs. 3c-f). MERRA generally overestimates $\mathrm{SW}_{\text {rad }}$ relative to the GEWEX-SRB over large areas during local summer but slightly underestimates
$\mathrm{SW}_{\mathrm{rad}}$ in portions of the tropics, while differences between GEOS-4 and the GEWEX-SRB product are more spatially complex. In the austral summer [DecemberFebruary (DJF)], the MERRA SW rad estimates show a positive discrepancy $\left(>2 \mathrm{MJ} \mathrm{m}^{-2}\right.$ day $\left.^{-1}\right)$ for over $60 \%$ of Southern Hemisphere (SH) land areas. In contrast, GEOS-4 underestimates $\mathrm{SW}_{\text {rad }}$ over most $\mathrm{SH}$ land areas during this period. The GEOS-4 results also underestimate $\mathrm{SW}_{\mathrm{rad}}$ in most of the northern midlatitudes, contrasting with a small positive discrepancy in MERRA $S W_{\text {rad }}$ for these regions during the DJF period. In the northern summer [July-August (JJA)], MERRA shows a positive $\mathrm{SW}_{\text {rad }}$ discrepancy (2 MJ $\mathrm{m}^{-2}$ day ${ }^{-1}$ ) relative to the GEWEX-SRB over $45 \%$ of the Northern Hemisphere (NH) land area, mostly in midlatitudes $\left(30^{\circ} \sim 60^{\circ} \mathrm{N}\right)$ including the Tibetan Plateau and northern Eurasia, but with a small negative discrepancy in portions of the northern tropics. A strong negative GEOS-4 $\mathrm{SW}_{\mathrm{rad}}$ discrepancy $\left(>2 \mathrm{MJ} \mathrm{m}^{-2}\right.$ day $^{-1}$ ) relative to GEWEX SRB occurs during the JJA period for the northern high latitudes above $60^{\circ} \mathrm{N}$ and also in arid regions including the Sahara Desert and 
(a)

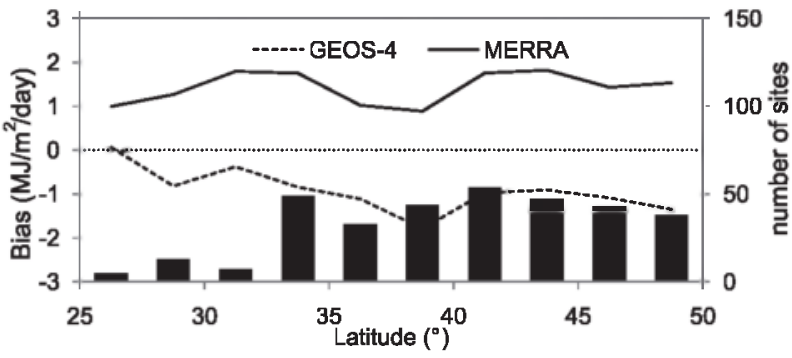

(b)

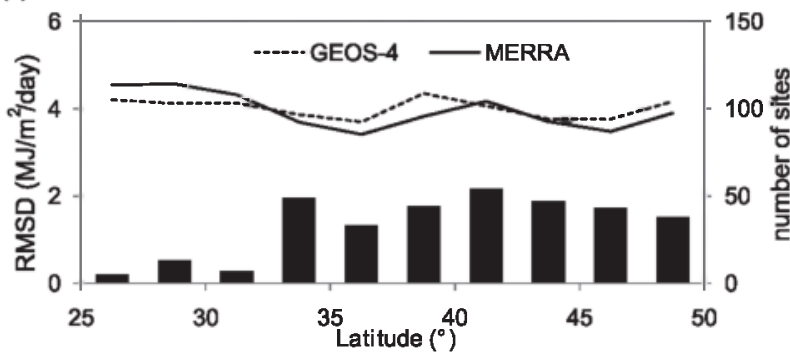

FIG. 4. (a) Bias and (b) RMSD of GEOS-4 and MERRA SW vs in situ observations in the contiguous United States from 2001 and 2002; bars show the number of sites in each $2.5^{\circ}$ latitudinal bin

Arabian Peninsula. The GEOS-4 JJA results also slightly overestimate $\mathrm{SW}_{\mathrm{rad}}$ in most of the $\mathrm{NH}$ midlatitudes and portions of western Amazonia and central Africa.

We also analyzed bias and RMSD values for MERRA

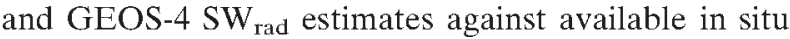
observations within CONUS (Fig. 1b) for a two-year period (2001-02) as summarized in Fig. 4. The latitudinal patterns of $\mathrm{SW}_{\text {rad }}$ bias and RMSD values for MERRA and GEOS-4 against the CONUS in situ data are similar to the previous global comparisons against the GEWEXSRB results (Figs. 2 and 3). MERRA shows a mean positive bias of $1.43 \mathrm{MJ} \mathrm{m}^{-2}$ day $^{-1}$, while GEOS-4 shows a mean bias of $-0.92 \mathrm{MJ} \mathrm{m}^{-2}$ day $^{-1}$. Both MERRA and GEOS-4 show similar mean RMSD values of approximately 4.0 $\mathrm{MJ} \mathrm{m}^{-2}$ day $^{-1}$ (Fig. 4b).
The patterns of MERRA and GEOS-4 SW $\mathrm{Wad}_{\text {accu- }}$ racy versus selected tower site observations in arid regions and northern high latitudes $\left(>60^{\circ} \mathrm{N}\right)$ are also consistent with the comparisons against GEWEX-SRB in those areas (Table 2). At these sites, MERRA generally shows higher correspondence and much reduced biases with the tower observations than GEOS-4. At the arid sites, the GEOS-4 SW rad $_{\text {estimates show large }}$ negative bias ( $>2 \mathrm{MJ} \mathrm{m}^{-2} \mathrm{day}^{-1}$ ) and RMSD values $\left(4 \sim 5 \mathrm{MJ} \mathrm{m}^{-2}\right.$ day $\left.^{-1}\right)$ relative to the tower site observations, in contrast with a small positive bias $\left(<1 \mathrm{MJ} \mathrm{m}^{-2}\right.$ day $\left.^{-1}\right)$ and low RMSD values in MERRA. At the northern sites, MERRA generally overestimates $\mathrm{SW}_{\mathrm{rad}}\left(0.3 \sim 1.5 \mathrm{MJ} \mathrm{m}^{-2}\right.$ day $\left.^{-1}\right)$ except at an Alaska site, while the GEOS-4 generally underestimates $\mathrm{SW}_{\text {rad }}$ $\left(0 \sim 3.63 \mathrm{MJ} \mathrm{m}^{-2} \mathrm{day}^{-1}\right)$ and shows large RMSD values $\left(3.08 \sim 6.53 \mathrm{MJ} \mathrm{m}^{-2}\right.$ day $^{-1}$ ) with the exception of a Finland site.

\section{b. Surface air temperatures and vapor pressure deficit}

Global patterns of temporal correlations between MERRA and AMSR-E UM daily air temperature estimates are presented in Figs. 5a and 5b. Overall, the two datasets show higher temporal correspondence for $T_{\max }(R=0.67$, Fig. $5 \mathrm{a})$ than for $T_{\min }(R=0.62$, Fig. $5 \mathrm{~b})$ anomalies. The two temperature anomaly datasets show higher correspondence in the middle and high latitudes $\left(>30^{\circ} \mathrm{N}-\mathrm{S}\right.$, except for portions of the Tibetan Plateau), than in the tropics. Low correlations in tropical nondesert regions are partially explained by characteristically low temporal variability in the daily and seasonal temperature ranges. Lower correlations in tropical desert areas also reflect greater microwave emissivity variations in these regions that influence the AMSR-E (UM) temperature retrievals (Jones et al. 2010). However, the temperature climatology was calculated from a relatively short period (2003-06), which may cause uncertainty in the temperature correlation analysis.

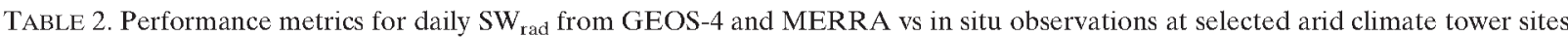
( 3 sites) and northern $\left(>60^{\circ} \mathrm{N}\right)$ sites $(6$ sites). For the arid sites, observed annual precipitation $(P)$ is also shown.

\begin{tabular}{|c|c|c|c|c|c|c|c|c|c|}
\hline \multirow[b]{2}{*}{ Site } & \multirow[b]{2}{*}{ Year } & \multirow[b]{2}{*}{ location } & \multirow[b]{2}{*}{$P(\mathrm{~mm})$} & \multicolumn{2}{|c|}{$R$} & \multicolumn{2}{|c|}{$\begin{array}{c}\text { Bias } \\
\left(\mathrm{MJ} \mathrm{m}^{-2} \text { day }^{-1}\right)\end{array}$} & \multicolumn{2}{|c|}{$\begin{array}{c}\text { RMSD } \\
\left(\mathrm{MJ} \mathrm{m}^{-2} \text { day }^{-1}\right)\end{array}$} \\
\hline & & & & MERRA & GEOS-4 & MERRA & GEOS-4 & MERRA & GEOS-4 \\
\hline IL-Yat (Israel) & $2001-06$ & $31.35^{\circ} \mathrm{N}, 35.05^{\circ} \mathrm{E}$ & 267 & 0.91 & 0.88 & 0.19 & -2.62 & 3.45 & 4.96 \\
\hline BW-Ma1 (Botswana) & $2000-01$ & $19.92^{\circ} \mathrm{S}, 23.56^{\circ} \mathrm{E}$ & 329 & 0.63 & 0.56 & 0.80 & -2.43 & 4.25 & 4.91 \\
\hline USSRM (Arizona) & $2004-06$ & $31.82^{\circ} \mathrm{N}, 110.87^{\circ} \mathrm{W}$ & 314 & 0.92 & 0.88 & 1.11 & -2.02 & 2.99 & 3.96 \\
\hline RUChe (Russia) & $2002-05$ & $68.61^{\circ} \mathrm{N}, 161.34^{\circ} \mathrm{E}$ & & 0.90 & 0.84 & 0.32 & -2.91 & 4.07 & 5.58 \\
\hline FI-Hyy (Finland) & $2000-06$ & $61.85^{\circ} \mathrm{N}, 24.29^{\circ} \mathrm{E}$ & & 0.94 & 0.93 & 1.50 & 0.62 & 3.52 & 3.09 \\
\hline FI-Kaa (Finland) & $2000-06$ & $69.14^{\circ} \mathrm{N}, 27.30^{\circ} \mathrm{E}$ & & 0.92 & 0.88 & 0.46 & -1.48 & 3.28 & 3.90 \\
\hline FI-Sod (Finland) & $2000-06$ & $67.36^{\circ} \mathrm{N}, 26.64^{\circ} \mathrm{E}$ & & 0.94 & 0.93 & 0.80 & -1.14 & 2.98 & 3.07 \\
\hline SE-Deg (Sweden) & $2001-05$ & $64.19^{\circ} \mathrm{N}, 19.56^{\circ} \mathrm{E}$ & & 0.94 & 0.92 & 0.95 & -0.01 & 3.06 & 3.08 \\
\hline USIvo (Alaska) & $2003-06$ & $68.49^{\circ} \mathrm{N}, 155.75^{\circ} \mathrm{W}$ & & 0.93 & 0.82 & -0.64 & -3.63 & 3.46 & 6.53 \\
\hline
\end{tabular}




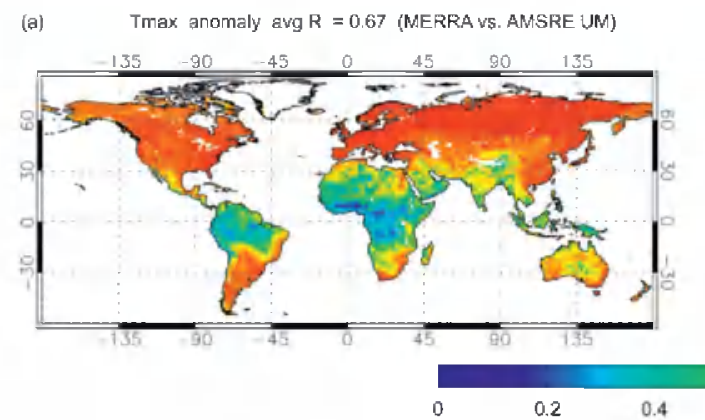

(b) Tmin anomaly avg $\mathrm{R}=0.62$ (MERRA vs. AMSRE UM)

(c) Tmax avg dfference $=-0.96^{\circ} \mathrm{C}$ ịERRA - AMSRE UM)
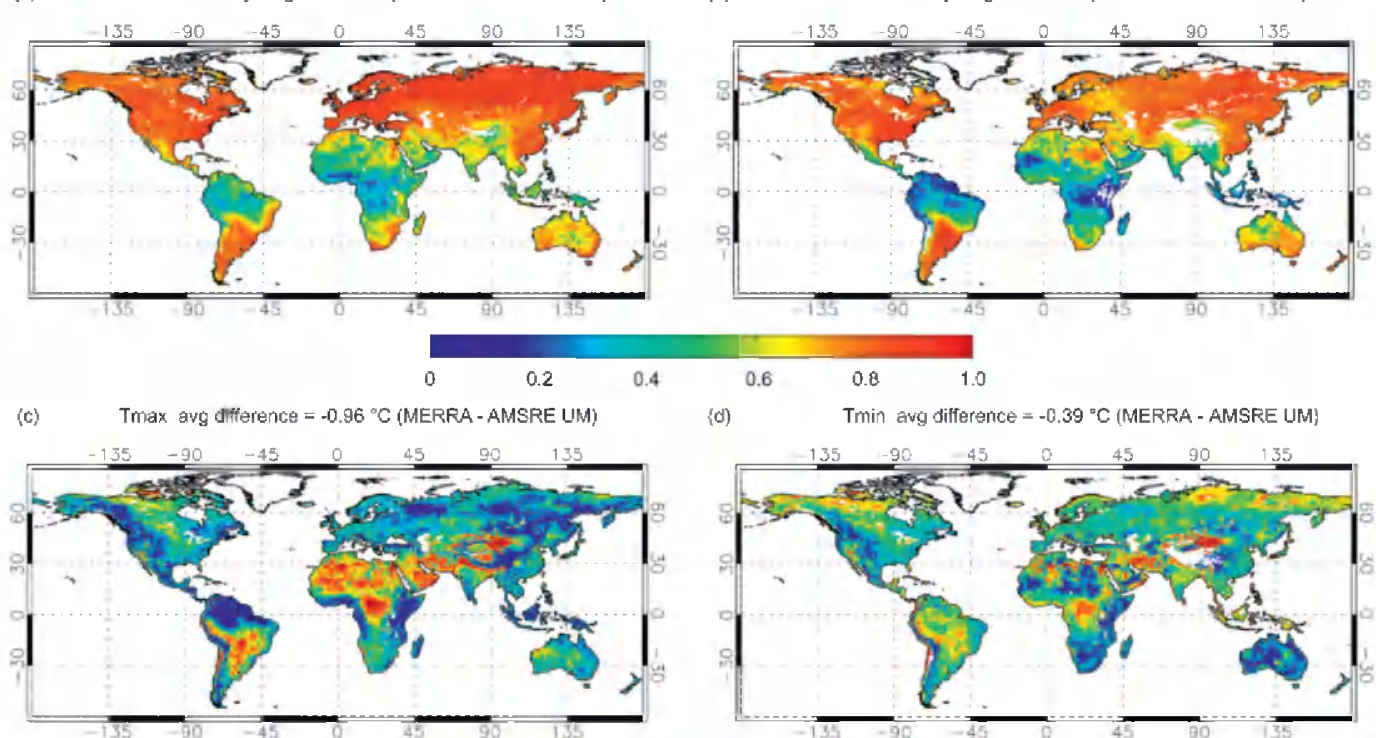

(d)

Trmin awg difference $=-0.39^{\circ} \mathrm{C}$ (MERRA - AMSRE UM)
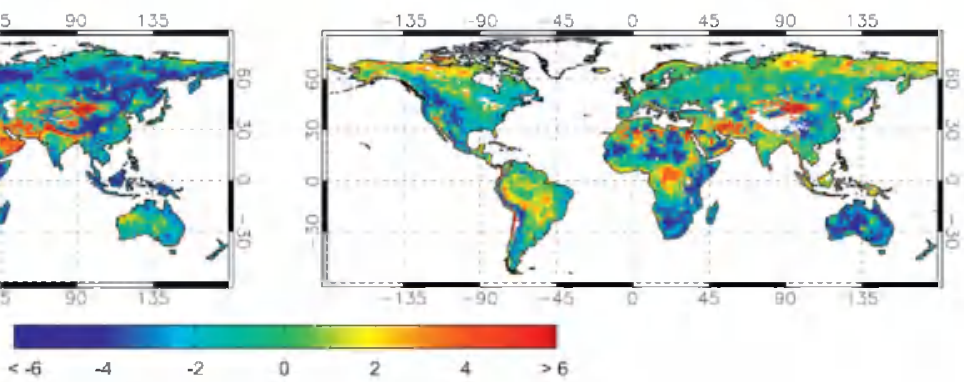

$<\begin{array}{ccccc}-6 & -4 & -2 & 0\end{array}$

(e) Tmax avg RMSD = 4.1 ${ }^{\circ} \mathrm{C}$ (MERRA ws. AMISRE UM)

(f)

TMin avg RMSD $=3.4^{\circ} \mathrm{C}$ (MERRA vg. AMSRE UM)

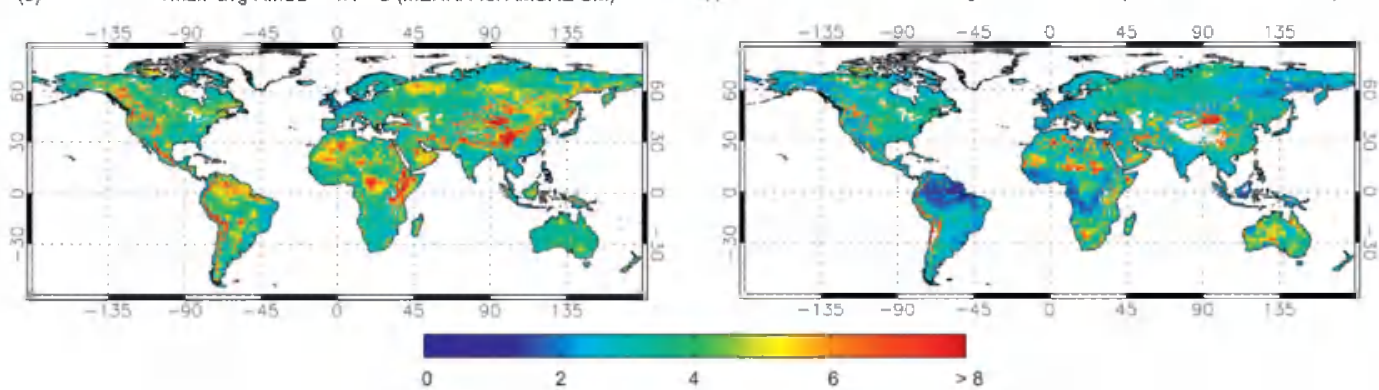

FIG. 5. (a),(b) Correlation coefficient $(R)$ between MERRA and AMSR-E UM daily (left) $T_{\max }$ and (right) $T_{\min }$ anomalies; (c)-(f) mean difference $\left({ }^{\circ} \mathrm{C}\right.$ ) and RMSD $\left({ }^{\circ} \mathrm{C}\right)$ values between MERRA and AMSR-E UM retrieved daily (left) $T_{\max }$ and (right) $T_{\min }$. The daily temperature anomalies were calculated based on a climatology averaged from 2003 to 2006. The $R$, global multiyear average difference, and RMSD from 2003 to 2006 are provided at the top of the panels. Areas outside the study domain or with insufficient retrievals $(<100)$ were masked from the analysis and are shown in white.

MERRA shows an overall larger discrepancy relative to AMSR-E UM in $T_{\max }$, with mean difference of $-0.96^{\circ} \mathrm{C}$ and RMSD of $4.1^{\circ} \mathrm{C}$, than in $T_{\min }$ with mean difference of $-0.39^{\circ} \mathrm{C}$ and RMSD of $3.4^{\circ} \mathrm{C}$ (Figs. 5c-f). MERRA generally underestimates $T_{\max }$ relative to AMSR-E for most NH areas but overestimates $T_{\max }$ for most SH land areas. Relative large $\left(>3^{\circ} \mathrm{C}\right)$ differences can be found in mountainous areas such as the Tibetan Plateau and western North America and some desert regions such as the Sahara desert and Middle East. The overestimation in MERRA $T_{\max }$ in SH areas, especially in South America, and different signs of differences in northern Amazonia and African rain forest areas are associated with the MERRA cloud patterns relative to GEWEX-SRB in those areas (Fig. 3b). The MERRA and AMSR-E $T_{\min }$ results also show a large negative discrepancy $\left(>3^{\circ} \mathrm{C}\right)$ in some arid and mountainous areas including the western United States, portions of the Sahara desert, southern Africa, and Australia.

The latitudinal and seasonal distributions of mean differences between MERRA and GEOS- 4 daily $T_{\max }$, $T_{\text {min }}$, and VPD results are depicted in Fig. 6. MERRA typically shows warmer and drier conditions in most of the low and midlatitudes $\left(<50^{\circ} \mathrm{N}-\mathrm{S}\right)$ during local summer relative to GEOS-4 (Fig. 6a), which is consistent with the overall positive discrepancy in MERRA $S W_{\text {rad }}$ relative to GEOS-4 (Fig. 3). In these areas, MERRA shows large diurnal variations in temperatures with larger difference in $T_{\max }$ than in $T_{\min }$ but a reduced dynamic range relative to GEOS- 4 above $50^{\circ} \mathrm{N}$ in the 
(a)

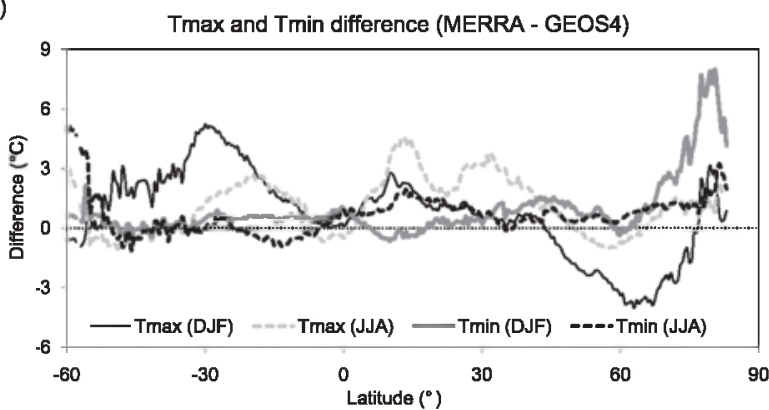

(b)

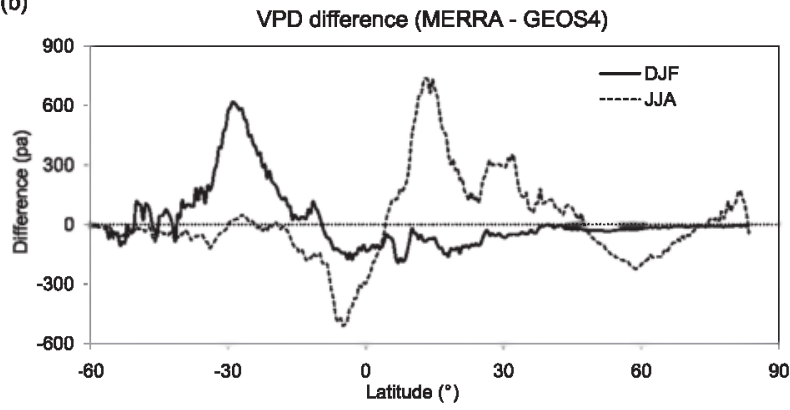

FIG. 6. Latitudinal distributions of mean difference between MERRA and GEOS-4 daily (a) land surface $T_{\max }$ and $T_{\min }$ and (b) VPD.

boreal winter (DJF). The characteristically warmer temperatures of MERRA in the low and midlatitudes generally result in larger MERRA VPD estimates in those areas for both seasons (Fig. 6b). In the DJF period, MERRA shows generally warmer conditions in the SH region resulting in overestimation of VPD and slightly wetter conditions [higher actual vapor pressure (AVP)] in the northern tropics resulting in a slight underestimation of VPD. In the JJA period, MERRA shows generally wetter and colder conditions in the southern tropics resulting in VPD underestimation, and warmer conditions in $\mathrm{NH}$ low and middle latitudes $\left(<40^{\circ} \mathrm{N}\right)$ resulting in VPD overestimation relative to GEOS- 4 .

The latitudinal dependence of the mean bias and RMSD in relation to WMO in situ observations for the MERRA, GEOS-4, and AMSR-E UM $T_{\min }$ and $T_{\max }$ daily estimates is presented in Figs. 7a-d. The bias patterns of the three products versus WMO stations are consistent with the differences among these products discussed above, although they have overall similar performance with latitudinal bias and RMSD values generally less than $2^{\circ}$ and $4^{\circ} \mathrm{C}$, respectively. GEOS- 4 shows a reduced diurnal temperature range, especially in the northern tropics, with a general cold bias $\left(>2^{\circ} \mathrm{C}\right)$ in the tropics for $T_{\max }$ and an overall warm bias for $T_{\min }$; MERRA generally shows a warm bias for $T_{\max }$ in most $\mathrm{SH}$ areas and a cold bias near the equator, and an overall warm bias for $T_{\min }$. The MERRA temperatures also show reduced biases and RMSD values in the northern high latitudes $\left(>0^{\circ} \mathrm{N}\right)$ relative to GEOS-4. The uncertainty in the AMSR-E UM algorithms in desert areas may contribute to large biases and RMSD $\left(>3^{\circ} \mathrm{C}\right)$ values of the AMSR-E UM temperatures relative to WMO observations in the northern tropics, especially in $T_{\min }$. The three datasets also show generally larger biases in SH and tropical regions, which partially reflect the reduced number of available WMO stations in these areas.

Globally, the MERRA, GEOS-4, and AMSR-E UM datasets have a mean temperature bias of less than $1^{\circ} \mathrm{C}$ and RMSD of less than $4^{\circ} \mathrm{C}$ for both $T_{\max }$ and $T_{\min }$ relative to the WMO observations (Table 3 ). Among the three datasets, MERRA $T_{\max }$ and $T_{\min }$ results show the highest correlation $(R>0.9)$ and lowest $\operatorname{RMSD}\left(<3^{\circ} \mathrm{C}\right)$ with the WMO observations. The MERRA results also show a warm bias $\left(\sim 1^{\circ} \mathrm{C}\right)$ for $T_{\min }$ but no apparent bias for $T_{\max }$. The GEOS-4 results show a general cold bias for $T_{\text {max }}$ and warm bias for $T_{\text {min }}$. The AMSR-E UM results show a warm bias for both $T_{\max }$ and $T_{\min }$. It should be noted that these global statistics are weighted toward the $\mathrm{NH}$ middle latitudes, which have a much higher WMO station density than other areas. Also, the statistics at seasonal scales are not given because AMSR-E temperatures are largely constrained with frozen conditions and snow present and incomplete temporal coverage in the winter may introduce bias to global averages at different seasons.

The biases of MERRA and GEOS-4 daily VPD estimates relative to the WMO observations show similar latitudinal patterns as the temperature comparisons (Figs. 7e-f). The VPD biases are strongly influenced by MERRA-GEOS-4 daily air temperature biases, which introduce error into the saturated vapor pressure $\left(e_{\mathrm{sat}}\right)$ calculations used to compute VPD; these errors are compounded under warmer temperatures due to the near-exponential relationship between air temperature and $e_{\text {sat }}$. Therefore, larger biases $(>300$ pa) and RMSD values in MERRA-GEOS-4 VPD can be found in the tropics and SH middle latitudes. Comparatively, the biases in MERRA-GEOS-4 AVP are smaller $(<100 \mathrm{pa}$, not shown). Globally, the MERRA VPD results have slightly higher correlation $(R=0.83)$, and lower bias and RMSD relative to the WMO observations (Table 3 ). As with the temperature results, the global AVP-VPD statistics are also weighted toward $\mathrm{NH}$ middle latitude regions.

\section{c. Surface soil moisture}

The MERRA daily surface soil moisture results show similar global patterns of correspondence with the two 
(a)

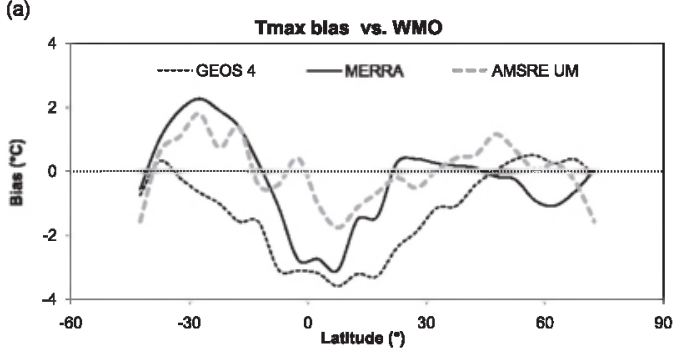

(c)

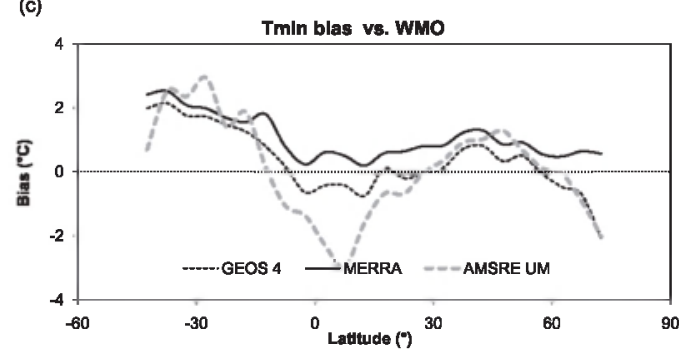

(e)

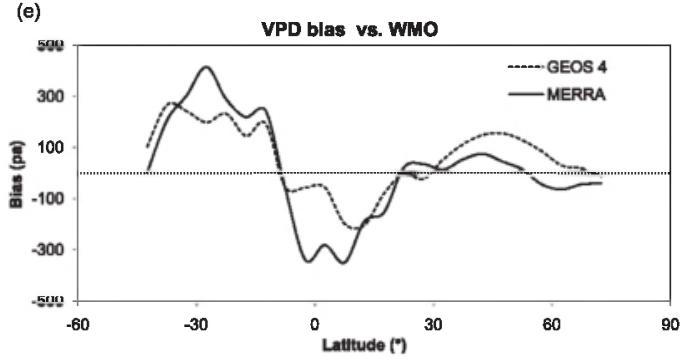

(b)

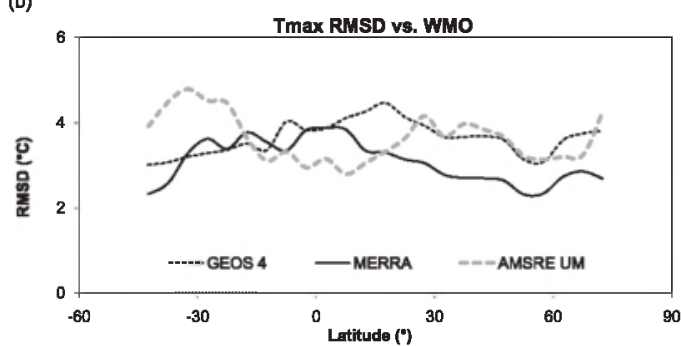

(d)

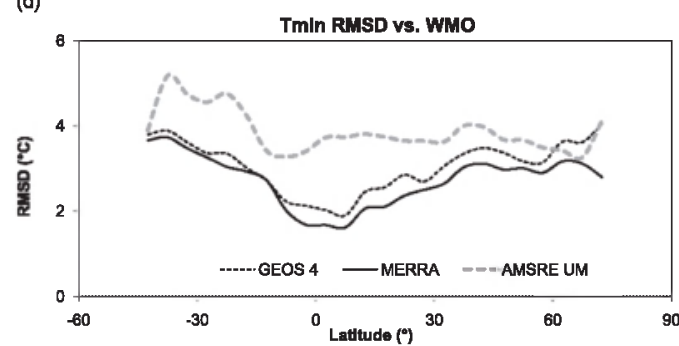

(i)

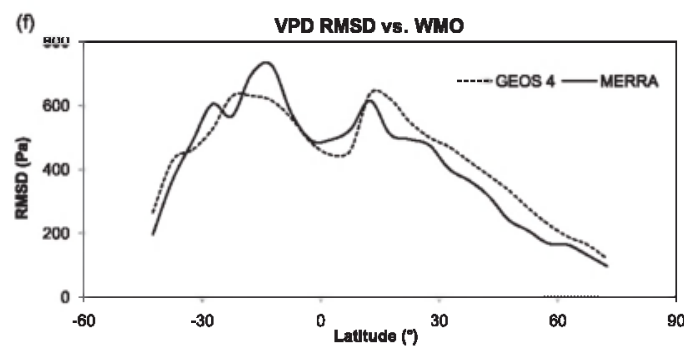

FIG. 7. (left) Bias and (right) RMSD of daily (a),(b) $T_{\max }$, (c),(d) $T_{\min }$, and (e),(f) VPD from GEOS-4, MERRA, and AMSR-E UM vs WMO observations. All bias and RMSD values were computed from 2000 to 2006 data for GEOS-4 and MERRA and from 2003 to 2006 data for AMSRE UM for each $5^{\circ}$ latitudinal bin.

AMSR-E surface soil moisture products (Figs. 8a,b). Relatively strong soil moisture correlations occur in areas with low to moderate vegetation cover and characteristically larger seasonal soil moisture variability (see below), including portions of India, the Sahel, Kazakhstan, Australia, and the north-central United States. The MERRA soil moisture results show overall higher correspondence with the AMSR-E VU data $(R=$ $0.49)$ than the UM data $(R=0.38)$, with negatively correlated pixels excluded from the statistics. Negative correlations occur mostly in the VU product over the northern high latitudes and in the Sahara desert region for the UM soil moisture product.
The AMSR-E soil moisture retrievals are subject to greater uncertainty in the high latitudes and desert regions, which may partially explain the negative correlations between MERRA and AMSR-E soil moisture. The MERRA and AMSR-E VU soil moisture results show significant negative correlations $(p<0.05)$ in highlatitude boreal and arctic areas. These areas coincide with a relatively high fraction of open water cover in the summer (Fig. 8c), which may adversely affect the VU soil moisture retrievals. The MERRA and AMSR-E UM soil moisture results also show relatively low correspondence in these regions. The AMSR-E retrievals for these northern areas are sparse relative to other

TABLE 3. Comparisons of MERRA, GEOS-4 and AMSR-E UM daily meteorology against WMO station observations. The comparison period for GEOS-4 and MERRA datasets is from 2000 to 2006 and from 2003 to 2006 for the AMSR-E dataset. The results were based on the same temporal mask.

\begin{tabular}{lccc}
\hline \hline & $R$ & Bias $\left({ }^{\circ} \mathrm{C}\right)$ & RMSD $\left({ }^{\circ} \mathrm{C}\right)$ \\
& $T_{\max ^{-}-T_{\min ^{-}}-\mathrm{VPD}}$ & $T_{\max }-T_{\min }-\mathrm{VPD}$ & $T_{\max }-T_{\min }-\mathrm{VPD}$ \\
\hline MERRA vs WMO & $0.93-0.91-0.83$ & $-0.05-1.02-37.1$ & $2.76-2.92-329.7$ \\
GEOS-4 vs WMO & $0.90-0.89-0.79$ & $-0.59-0.44-101.3$ & $3.57-3.25-384.3$ \\
AMSR-E UM vs WMO & $0.91-0.87$ & $0.41-0.67$ & $3.68-3.82$ \\
\hline
\end{tabular}


(a)

$\operatorname{avg} \mathrm{R}=0.38$ (MERRA vs AMSRE UM)

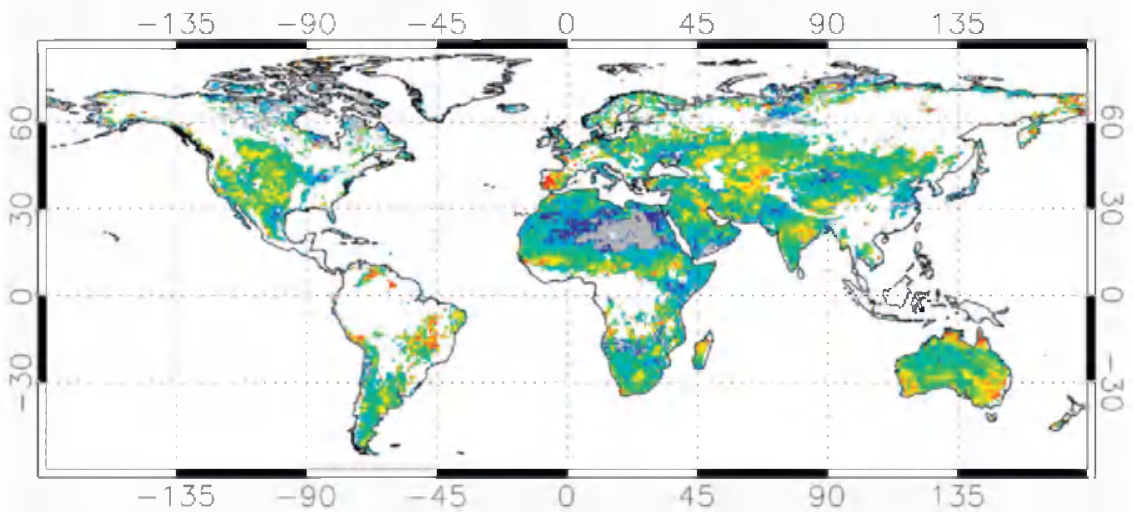

(b)

$\operatorname{avg} \mathrm{R}=0.49$ (MERRA vs AMSRE VU)

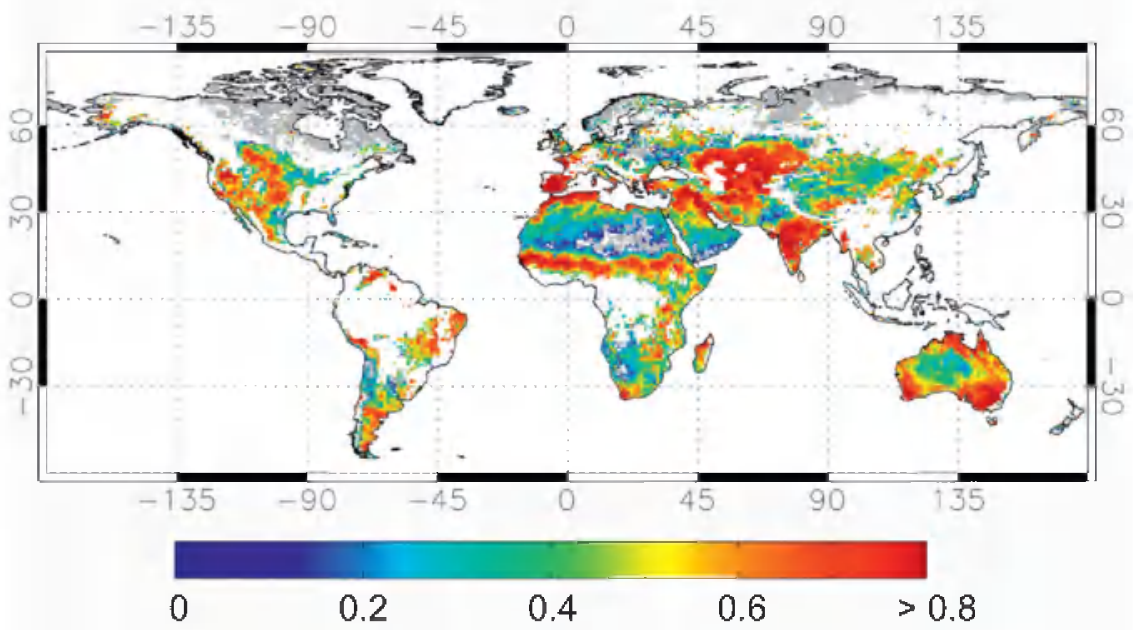

(c) open water fraction in July and August (AMSR-E UM)

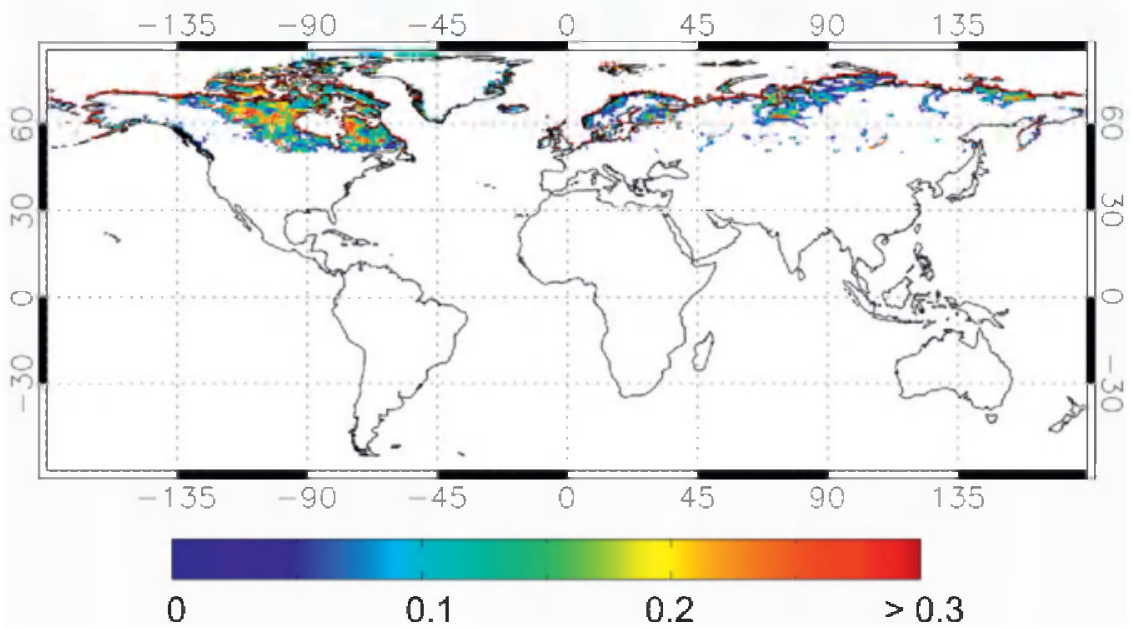

FIG. 8. Correlations $(R)$ between MERRA and AMSR-E daily surface soil moisture: (a) UM and (b) VU. (c) AMSR-E UM retrieved open water fraction in the summer (July and August) above $50^{\circ} \mathrm{N}$. All the results were averaged from 2003 to 2006 . Areas with insignificant correlations $(p>0.05)$, insufficient retrievals or outside the study domain are shown in white; areas with significant negative correlations $(p<0.05)$ are shown in gray. 

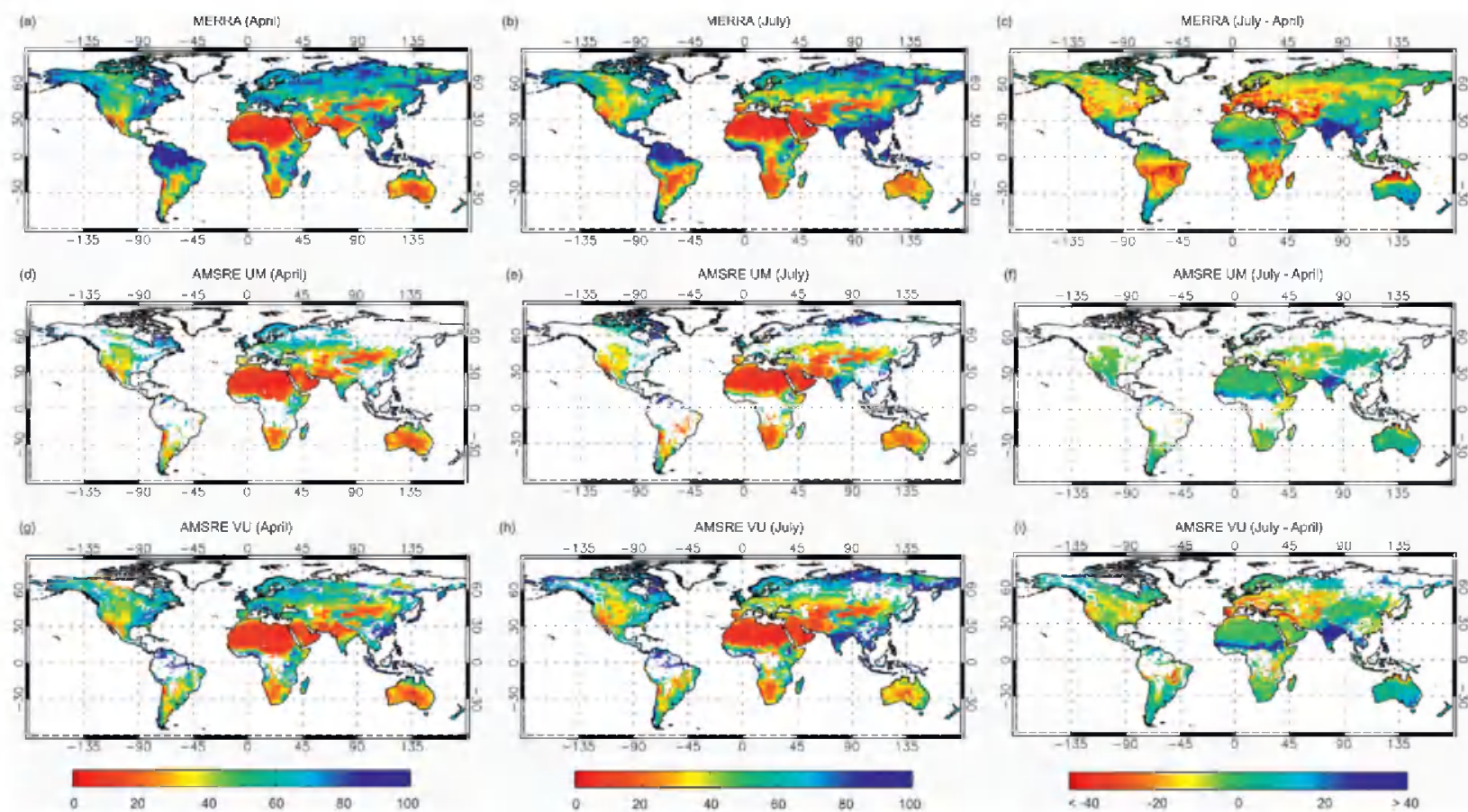

FIG. 9. Seasonal [(left) April and (middle) July] and (right) mean differences (top) MERRA, and AMSR-E 2003-2006 (middle) UM and (right) VU daily surface soil wetness (\%). Areas with insufficient retrievals or outside of the study domain are shown in white.

regions due to screening of frozen conditions and high vegetation biomass. The characteristic dry conditions and low soil moisture variations in arid regions, for example, the Sahara Desert, and large variability in microwave emissivity in these regions also cause low correspondence between MERRA and AMSR-E soil moisture.

The MERRA surface soil moisture results generally show characteristic global patterns of soil moisture seasonal changes (Figs. 9a-c). Most NH middle-latitude areas show characteristically wet soils in the spring that dry out over the summer months, while in Southeast Asia and the Indian peninsula soil moisture dynamics closely follow the tropical NH summer monsoon. Drier soils are observed in July in central and eastern Amazonia and Africa, which corresponds with the occurrence of the local dry season. In Australia, the MERRA surface soil moisture wets and dries in response to regional shifts in seasonal rainfall from northern areas in January to southeastern areas in July (Draper et al. 2009).

The MERRA results show overall similar seasonal patterns as the two AMSR-E surface soil moisture datasets in the low and middle latitudes but with generally stronger seasonal variation. (Figs. 9d-i). For example, the characteristic patterns of spring wetting in central Asia and northern Europe and gradual summer drying in the north-central United States are evident in both MERRA and AMSR-E results. The influence of local precipitation seasonality on surface soil moisture is also evident in the Indian Peninsula and Australia. Great uncertainty remains in both MERRA and AMSR-E soil moisture products in the high latitudes. In the northern latitudes, the AMSR-E soil moisture retrievals are largely constrained by seasonal frozen conditions. In contrast, the MERRA results show relatively high soil moisture levels in the boreal latitudes in April, including northern Siberia, which is still predominantly frozen at that time (Takala et al. 2009). The AMSR-E VU soil moisture results also show relatively high soil moisture in the northern high latitudes in April and July. This persistently wet state may be due to the influence of regionally extensive open water cover on the VU retrievals (e.g., Fig. 8c).

Table 4 summarizes the temporal correspondence between MERRA daily soil moisture and monthly precipitation estimates and coincident in situ measurements of these parameters at 26 selected tower sites across the CONUS region $\left(<50^{\circ} \mathrm{N}\right)$. Statistical correspondence was also assessed between the AMSR-E soil moisture retrievals and available in situ observations. The MERRA surface soil moisture estimates show significantly better temporal correspondence with in situ soil moisture measurements than the two AMSR-E soil moisture products for all biome types except croplands, with the largest differences in correlations for high biomass sites (e.g., forests). The MERRA surface soil moisture 
TABLE 4. Correlation coefficients $(R)$ vs AmeriFlux tower in situ observations for MERRA monthly precipitation $(P)$ and MERRA and AMSR-E daily surface soil moisture. The number of tower sites represented in each land cover category is noted, while the approximate $95 \%$ confidence intervals of the correlation coefficients are also given. Note the following: GRS = grassland; WSA = woody savannah/ savannah; CRP = cropland; ENF = evergreen needle-leaf forest; DBF = deciduous broadleaf forest; and MXF = mixed evergreen needle-leaf and deciduous broadleaf forest.

\begin{tabular}{|c|c|c|c|c|c|c|c|c|c|c|}
\hline & & & & \multirow[b]{3}{*}{$N$} & \multicolumn{6}{|c|}{ Soil moisture (daily) } \\
\hline & \multicolumn{3}{|c|}{ MERRA $P$ (monthly) } & & \multicolumn{2}{|c|}{ MERRA } & \multicolumn{2}{|c|}{ AMSR-E UM } & \multicolumn{2}{|c|}{ AMSR-E VU } \\
\hline & $N$ & $R$ & $N(p<0.005)$ & & $R$ & $N(p<0.001)$ & $R$ & $N(p<0.001)$ & $R$ & $N(p<0.001)$ \\
\hline GRS & 7 & $0.78 \pm 0.05$ & 7 & 7 & $0.48 \pm 0.02$ & 6 & $0.39 \pm 0.02$ & 5 & $0.38 \pm 0.02$ & 5 \\
\hline WSA & 5 & $0.81 \pm 0.06$ & 5 & 5 & $0.65 \pm 0.02$ & 5 & $0.34 \pm 0.04$ & 3 & $0.30 \pm 0.03$ & 3 \\
\hline CRP & 3 & $0.67 \pm 0.08$ & 3 & 3 & $0.23 \pm 0.04$ & 2 & $0.34 \pm 0.04$ & 3 & $0.23 \pm 0.04$ & 2 \\
\hline $\mathrm{ENF}$ & 4 & $0.81 \pm 0.05$ & 4 & 4 & $0.67 \pm 0.04$ & 4 & $0.13 \pm 0.06$ & 1 & $0.20 \pm 0.06$ & 2 \\
\hline DBF & 4 & $0.64 \pm 0.09$ & 4 & 1 & $0.62 \pm 0.06$ & 1 & $0.20 \pm 0.10$ & 1 & $0.30 \pm 0.10$ & 1 \\
\hline MXF & 3 & $0.71 \pm 0.09$ & 3 & 1 & $0.58 \pm 0.08$ & 1 & $0.36 \pm 0.10$ & 1 & $0.29 \pm 0.10$ & 1 \\
\hline All & 26 & $0.75 \pm 0.03$ & 26 & 21 & $0.53 \pm 0.01$ & 19 & $0.31 \pm 0.02$ & 14 & $0.30 \pm 0.02$ & 14 \\
\hline
\end{tabular}

results are significantly correlated $(R=0.53 \pm 0.01$, $p<0.001$ ) with observed soil moisture at all sites except for two sites composed of grassland and cropland cover types. The correspondence between MERRA and in situ surface soil moisture observations was not significantly different between forest and nonforest sites, although needle-leaf forest (ENF) and woody savannah sites showed the strongest correspondence. Relatively low correspondence between MERRA and observed soil moisture at the cropland sites may reflect human intervention activities such as irrigation. The MERRA monthly precipitation estimates correspond significantly $(R>0.6, p<$ 0.005 ) with the in situ precipitation measurements at all sites. The relative agreement between MERRA and in situ precipitation is proportional to the correspondence between MERRA and in situ soil moisture results, which indicates that accurate representation of precipitation is a major determinant of MERRA soil moisture accuracy at these middle-latitude sites.

In contrast, the soil moisture accuracies of the two AMSR-E products are insignificantly different from each other at these sites and closely related to vegetation canopy biomass. The reduced seasonality of AMSR-E soil moisture retrievals due to masking of higher vegetation canopy biomass (VOD) conditions, especially in densely vegetated areas (e.g., ENF) and the relatively shallow $(\sim 1 \mathrm{~cm})$ AMSR-E sensing depth reduce correlations with the in situ observations. The use of a combined 6.9- and $10.7-\mathrm{GHz}$ soil moisture dataset to reduce RFI impacts in the CONUS region should have only a minor influence on the correlation analysis. The two frequency soil moisture retrievals have similar spatial and temporal characteristics and marginal differences relative to differences between these shallow soil layer measurements and the deeper in situ soil layer measurements of the tower sites (Draper et al. 2009).
The above analysis indicates that precipitation plays a major role in MERRA soil moisture modeling in the midlatitudes. However, other factors may also impact MERRA soil moisture accuracy in mid- and highlatitude regions. Additional evaluation of the daily surface soil moisture time series was conducted at two tower sites representing woody savannah $\left(\sim 31.8^{\circ} \mathrm{N}\right)$ and boreal forest $\left(\sim 53.9^{\circ} \mathrm{N}\right)$ land cover types (Fig. 10). Figure 10 a represents a woody savannah tower site in Arizona (USSRM, $31.821^{\circ} \mathrm{N}, 110.866^{\circ} \mathrm{W}$ ). The MERRA soil moisture results correspond favorably with in situ soil moisture measurements for this site $(R=0.70$, $p<0.001)$. The two AMSR-E soil moisture datasets respond to all major rainfall events $(R>0.55, p<0.001)$ but show much greater daily variability than the site observed soil moisture series. The discrepancy between MERRA and in situ soil moisture is primarily due to differences between MERRA and in situ precipitation (not shown). MERRA overpredicts local precipitation $(>20 \mathrm{~mm})$ at the site from January to March and also in September (not shown), resulting in relative high MERRA surface soil moisture during these two periods. The USSRM site has an annual rainfall of $300 \mathrm{~mm}$ with a desert monsoon climate and most precipitation comes from single cloud cell type summer rainfall events. Therefore, a large precipitation discrepancy between a coarse-resolution reanalysis product such as MERRA and local point observations can be expected. The two AMSR-E products represent a shallower soil depth $(\leq 1 \mathrm{~cm})$ layer than the in situ measurements $(\leq 5 \mathrm{~cm})$ and thus show a higher frequency wetting and drying response. The larger temporal variability in AMSR-E surface moisture may also reflect diurnal $T_{b}$ and moisture differences between descending and ascending overpasses (Draper et al. 2009) that are neglected in the daily surface soil moisture composite. 

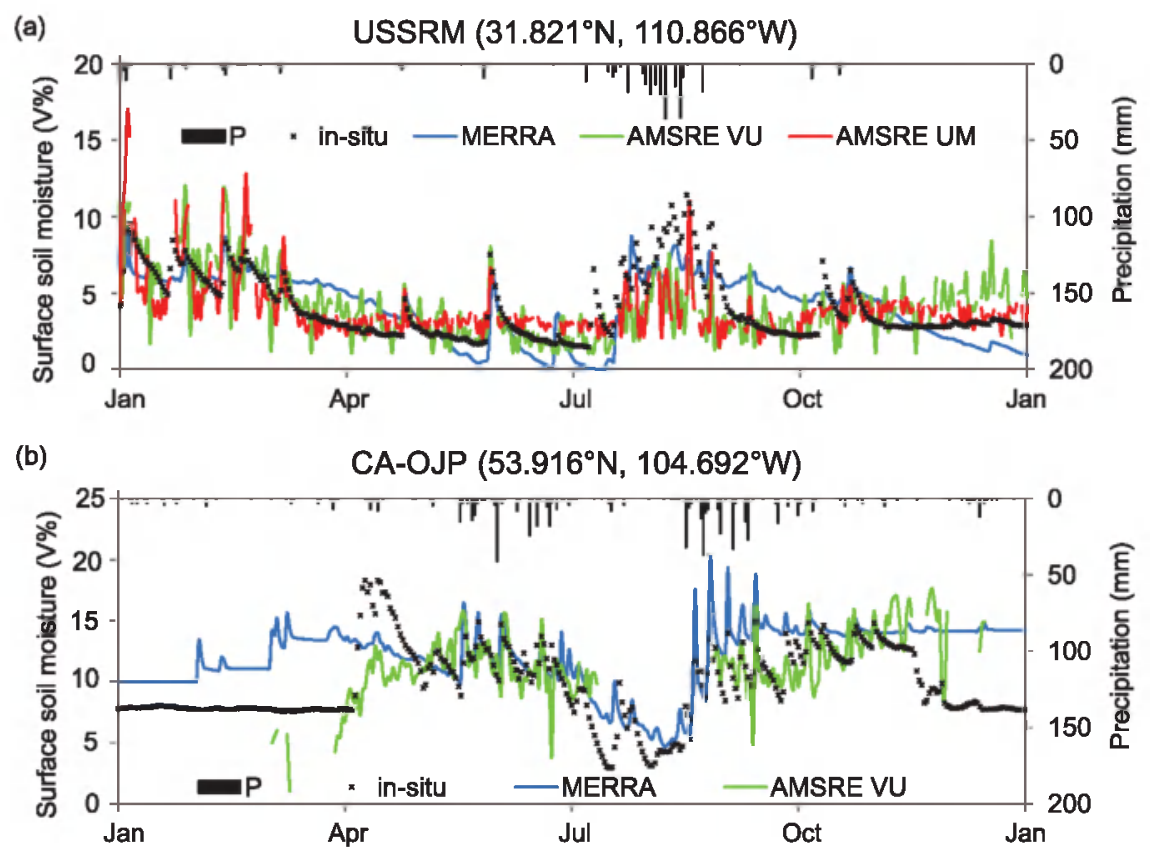

FIG. 10. Daily surface soil moisture (V\%) from in situ observations, MERRA and AMSR-E at a (a) woody savannah site (USSRM, $31.821^{\circ} \mathrm{N} 110.866^{\circ} \mathrm{W}$, soil depth $\leq 5 \mathrm{~cm}$ ) and (b) boreal old jack pine forest site (CA-OJP, $53.916{ }^{\circ} \mathrm{N} 104.692^{\circ} \mathrm{W}$, soil depth $\leq 15 \mathrm{~cm}$ ). Bars extending below top axes show daily in situ-precipitation.

Figure $10 \mathrm{~b}$ represents a boreal old jack pine forest tower site in Saskatchewan (CA-OJP, $53.916^{\circ} \mathrm{N}$, $104.692^{\circ} \mathrm{W}$ ). The AMSR-E retrievals are strongly constrained at this cold site owing to seasonal snow cover and frozen soil conditions in winter and high biomass (VOD) in the summer. We present only the AMSR-E VU data because the AMSR-E UM data produce relatively larger VOD levels, resulting in more extensive screening and an insufficient number of retrievals at this forest site. The AMSR-E VU ( $\sim 1-\mathrm{cm}$ depth) soil moisture series still show greater daily variability than the in situ observations ( $\leq 15-\mathrm{cm}$ depth) and are not available during the summer due to high VOD. The MERRA soil moisture results at this site generally correspond with the observed temporal variability and seasonal dry-down of the in situ soil moisture measurements during the annual nonfrozen period ( $R=0.62, p<0.001$ ). However, MERRA shows a soil moisture increase $2-3$ weeks early relative to site observations in the spring, indicating an earlier spring thaw in the model, even though MERRA slightly underestimates surface air temperature (bias = $2.66^{\circ} \mathrm{C}$ ) before April for this site (not shown). MERRA also shows generally higher soil moisture levels during the winter frozen season relative to the other seasons at the CA-OJP site, which is consistent with MERRA global patterns showing generally high soil moisture levels under predominantly frozen northern conditions in early spring (e.g., Fig. 9a).

\section{Discussion}

The results of this study indicate that the MERRA reanalysis provides overall improved predictions of land surface processes, with significant improvements in the northern high latitudes relative to the GEOS-4 products and currently available estimates from satellite microwave remote sensing. The improvement in MERRA cloud modeling relative to GEOS-4 contributes to better accuracy in MERRA land surface parameters including incident solar radiation and air temperatures. Accurate prediction of precipitation and application of the catchment land surface contribute to the favorable comparisons between MERRA and other soil moisture datasets, though great uncertainty still persists in both MERRA and AMSR-E soil moisture in the high latitudes.

The comparisons between MERRA-GEOS-4 and GEWEX-SRB solar radiation indicate that MERRA has a very different cloud pattern from GEOS-4, with reduced $\mathrm{SW}_{\text {rad }}$ uncertainty in the northern deserts and high latitudes. MERRA generally overestimates $S_{\text {rad }}$ in the midlatitudes but underestimates $\mathrm{SW}_{\mathrm{rad}}$ in the equatorial regions relative to the GEWEX-SRB. The comparisons between MERRA and Global Precipitation Climatology Project (GPCP) precipitation (Bosilovich et al. 2011) indicate that MERRA is affected by a sparse cloud effect in most of the middle latitudes and an excessive cloud effect in the tropics, which could explain the 
above discrepancy in $\mathrm{SW}_{\mathrm{rad}}$. In contrast, GEOS-4 generally underestimates $\mathrm{SW}_{\text {rad }}$ relative to the GEWEX$\mathrm{SRB}$, especially in the northern high latitudes and NH arid regions (e.g., Sahara Desert and Arabian Peninsula). Previous validation studies showed that GEOS-4 produced excessive precipitation throughout the globe, especially in the tropics, and thus had overall excessive cloud effects (Bloom et al. 2005). Previous comparisons between MERRA-GEOS-4 and GPCP precipitation also indicated that the overestimation of tropical precipitation is greatly reduced in MERRA relative to GEOS-4 (Bosilovich et al. 2008, 2011), which is consistent with the reduced uncertainty in MERRA $S_{\text {rad }}$ compared with GEOS-4 in these areas. The reason why GEOS-4 greatly underestimates $\mathrm{SW}_{\mathrm{rad}}\left(>4 \mathrm{MJ} \mathrm{m}^{-2}\right.$ day $\left.^{-1}\right)$ in northern $\left(>60^{\circ} \mathrm{N}\right)$ areas during the boreal summer is uncertain from the current study but may be caused by a deficiency in GEOS-4 cloud modeling in the high latitudes (Bloom et al. 2005). It should be noted that the GEWEX-SRB data were generated using GEOS atmospheric moisture and temperature profiles as background (first guess) estimates; the three datasets are therefore not completely independent. However, although the GEWEX-SRB version 3.0 dataset from this study utilized temperature and moisture profiles from the GEOS-4 system, the GEWEX-SRB algorithms also use additional information from satellite visible and infrared radiances and likely provide better cloud estimates than GEOS-4.

The cloud modeling and observation systems in GCMs have great impact on modeled land surface parameters, including air temperatures and VPD presented in this study. MERRA generally shows warmer and drier conditions (high air temperatures and VPD) relative to GEOS-4 and WMO observations especially in the SH and northern tropics, which is consistent with generally greater solar radiation and reduced clouds in MERRA. In contrast, GEOS-4 generally shows a reduced diurnal temperature range and cold bias in $T_{\max }$ in these areas, which is also consistent with GEOS-4 generally showing more cloud cover than MERRA throughout the globe. The MERRA and GEOS-4 products show a large temperature discrepancy $\left(>3^{\circ} \mathrm{C}\right)$ in the northern high latitudes $\left(>60^{\circ} \mathrm{N}\right)$, while comparisons against WMO station observations indicate that MERRA has a reduced temperature bias in these areas. The VPD discrepancy between MERRA and GEOS- 4 is mainly caused by the air temperature biases, especially in warmer areas. Both datasets show reduced biases relative to WMO stations for temperatures and VPD in the northern middle latitudes but larger biases in the $\mathrm{SH}$ and tropics. The heterogeneity of observations from the surface (mostly radiosonde) assimilated in GEOS systems may partly account for this difference, where NH land areas (especially North America and Europe) have greater observation densities relative to sparse observations over SH areas.

MERRA and AMSR-E air temperatures show large discrepancies in mountainous areas, deserts, and tropical regions because of topographically induced spatial heterogeneity and greater uncertainty in the MERRA cloud scheme and AMSR-E temperature algorithms. The MERRA topographic grid generally has a higher elevation than the NSIDC AMSR-E grid, with a mean difference of $120 \mathrm{~m}$ and substantial differences in mountainous areas (e.g., Tibetan Plateau, western United States, and west coast of South America). In these areas, MERRA generally underestimates $T_{\max }$ relative to AMSR-E and also shows a larger $T_{\min }$ difference. The MERRA and AMSR-E $T_{\max }$ and $T_{\min }$ results also show large differences in tropical desert areas, which likely reflect greater uncertainty in microwave emissivity and associated temperature retrievals in these sparsely-vegetated areas (Jones et al. 2010). The AMSR-E and MERRA $T_{\text {max }}$ differences show opposite signs in portions of Amazon and East Africa rain forests, which may be associated with different MERRA cloud patterns relative to the GEWEX-SRB (Fig. 3b). MERRA also overestimates $\mathrm{SW}_{\text {rad }}$ in most $\mathrm{SH}$ land areas, which is consistent with a positive MERRA $T_{\max }$ discrepancy relative to AMSR-E.

The MERRA surface soil moisture results generally capture observed soil wetting and drying processes in the low and middle latitudes and show favorable correlations with the two AMSR-E-based soil moisture products for areas with low to moderate vegetation biomass. Accurate prediction of precipitation in the middle latitudes and the application of the catchment land surface model (section 2) used in the GEOS-5 assimilation system may both contribute to the favorable temporal correspondence between MERRA and the other soil moisture datasets. The MERRA surface soil moisture accuracy in midlatitude regions shows minimal difference between forest and nonforest sites but is proportional to the accuracy of MERRA predicted precipitation. The MERRA precipitation data showed strong correspondence with in situ precipitation observations at all selected tower sites in this study. The catchment model considers the horizontal subgrid-scale heterogeneity in hydrological processes. Both of these modifications should improve model representation of hydrological processes in MERRA.

While precipitation accuracy largely influences soil moisture modeling accuracy in the middle latitudes, the accuracy of MERRA- and AMSR-E-derived surface soil moisture is also constrained by uncertainties in the 
modeling of seasonal snow and frozen soil processes in the high latitudes. The MERRA results indicate earlier spring snowmelt relative to the available in situ observations, though MERRA generally underestimates surface air temperature during winter. The catchment land surface model does consider the impact of thermodynamic changes in surface snow cover on water and energy cycling. However, the model still uses relatively simple approaches to represent soil freezing and thawing effects on subsurface thermodynamics and hydrological processes, which are important for accurate modeling of soil moisture and streamflow in the high latitudes (Cherkauer et al. 2003). The reduced MERRA soil moisture correlation with in situ measurements during northern high-latitude frozen to nonfrozen season transitions indicates that further effort is required to improve MERRA snow and soil freeze-thaw dynamics. Alternative soil moisture retrievals from satellite microwave remote sensing are limited in northern boreal forest and tundra regions by high biomass (VOD) levels, snow and frozen conditions, and extensive open water cover during the nonfrozen season.

Spatial-scale differences may contribute to discrepancies between the in situ station observations and regional products from global reanalysis and satellite microwave remote sensing retrievals. Soil moisture, in particular, has strong characteristic spatial heterogeneity (Scipal et al. 2008). The three independent soil moisture datasets employed in this study (including reanalysis, AMSR-E remote sensing retrievals, and in situ measurements) are strongly constrained by relatively coarse spatial scales and sparse observations in relation to characteristic soil moisture heterogeneity over much of the globe. Precipitation is a key factor influencing land surface hydrological cycles, but current climate simulation systems have difficulty providing accurate simulations of precipitation at finer spatial scales commensurate with landscape variability (Sheffield et al. 2006; Reichle et al. 2011). The poor spatial and temporal coverage of in situ observations and generally large spatial heterogeneity in surface soil moisture limits the potential assimilation value of these measurements for climate system reanalysis and the utility of these observations as effective ground truth for most areas of the globe.

The AMSR-E surface soil moisture retrievals generally coincide with major rainfall events represented by the available precipitation observations; similar satellite microwave remote sensing retrievals could provide valuable information for climate reanalysis. In the northern latitudes, microwave remote sensing can also provide accurate predictions of surface temperature and freeze-thaw processes (Jones et al. 2007, 2010). The assimilation of satellite microwave remote sensing based temperature and freeze-thaw retrievals may improve model predictions of snow and soil thermal and moisture changes during seasonal freeze-thaw transition periods. However, the relative coarse spatial scale of currently available passive microwave sensors (e.g., $\sim 25$-km for AMSR-E) and vegetation biomass constraints on higherfrequency (e.g., C- or X-band) microwave radiometric measurements of surface soil conditions limits their application for climate data assimilation. The NASA SMAP mission will provide global coverage and operational mapping of freeze-thaw state at $3-\mathrm{km}$ resolution with two-day precision and surface ( $\leq 5-\mathrm{cm}$ depth) soil moisture with a projected $0.04 \mathrm{~m}^{3} \mathrm{~m}^{-3}$ volumetric accuracy at 9-km spatial resolution (Entekhabi et al. 2010). The SMAP L-band active-passive microwave sensor will also improve soil moisture retrievals for moderately vegetated areas, with longer penetration depth and finer spatial resolution compared with other operational satellite passive microwave sensors. The planned SMAP freeze-thaw and soil moisture products are potentially useful for improving reanalysis simulations of land surface processes and will provide enhanced L-band sensitivity to land surface processes and finer spatial-scale inputs for ecosystem and hydrological models.

\section{Conclusions}

The NASA GMAO MERRA reanalysis is a prototype of the eventual system that will provide forcing inputs and land-modeling components for the SMAP Level 4 soil moisture and carbon products. In this study, MERRA estimates of selected land surface variables that are important for global ecological and hydrological studies were compared to similar variables from the precursor GEOS-4 system, independent satellite microwave remote sensing datasets derived from AMSR-E, and in situ observations distributed across the globe. Generally, MERRA provides similar accuracy or slightly better estimates of land surface meteorology compared with estimates from GEOS-4 and AMSR-E retrievals. The uncertainty of GEOS-4 incoming solar radiation in northern desert regions and high latitudes is greatly reduced in the MERRA reanalysis. The MERRA surface soil moisture results show advantages over the AMSR-E soil moisture products in the midlatitudes due to less limitation by dense vegetation. However, MERRA soil moisture accuracy is proportional to the accuracy of predicted precipitation, which is subject to uncertainty due to subgrid-scale spatial heterogeneity in topography and local weather conditions. Significant uncertainty also remains in MERRA surface soil moisture for the high latitudes. Assimilating surface temperature, soil 
moisture, and freeze-thaw information available from higher-resolution microwave remote sensing may improve model representation of snow and soil thermodynamic changes and hydrological cycles in those areas. SMAP will provide L-band active and passive microwave observations with enhanced spatial resolution that will enable better estimates of surface soil moisture and freeze-thaw changes than are currently available from AMSR-E and other operational satellite passive microwave sensors; these remote sensing observations should enable improved spatial resolution and soil moisture retrieval accuracy under higher biomass levels, with potentially improved assimilation value and reanalysis accuracy. Meanwhile, the GEOS assimilation system will be continually updated and advances in climate modeling and data assimilation will all contribute to better representation of land surface processes in the future analysis products.

Acknowledgments. Portions of this work were conducted at the Jet Propulsion Laboratory, California Institute of Technology and the University of Montana under contract to the National Aeronautics and Space Administration (NASA). This work was supported with funding from the NASA Hydrology and Terrestrial Ecology programs and the SMAP mission. The daily surface meteorology data was kindly provided by the National Climatic Data Center. We also thank the GSFC and ISLSCP for the MERRA, GEOS-4, and GEWEX-SRB datasets. The AmeriFlux network was supported by the U.S. Department of Energy and National Science Foundation as well as many local funders for individual sites (e.g., USDA CREES NRI 2004-35111-15057 and USDA NRI 2008-35101-19076).

\section{APPENDIX}

\section{Additional Data Descriptions and Data Processing}

\section{a. Temperature and humidity observations}

Daily $T_{\min }, T_{\max }$, and atmospheric vapor pressure measurements were obtained from the National Climatic Data Center (NCDC) Global Summary of the Day to evaluate the accuracy of the reanalysis and satellite remote sensing datasets. The daily observations were available at over $6000 \mathrm{WMO}$ weather stations from 2000 to 2006 (Fig. 1a).

\section{b. Solar radiation observations}

Because of the paucity of available global in situ surface solar radiation observations, the NASA-GEWEX-SRB database was used as a baseline to evaluate global patterns of relative uncertainty of SW $\mathrm{Sad}_{\text {in MERRA }}$ and GEOS-4. (http://eosweb.larc.nasa.gov/PRODOCS/ srb/table_srb.html). The dataset is generated using International Satellite Cloud Climatology Project (ISCCP) cloud fields and parameters and widely used as a reference for global shortwave radiation (Betts et al. 2006). The model uses the shortwave radiation algorithms of Pinker and Laszlo (1992) and background (or first guess) temperature and moisture profiles from the GMAO GEOS analysis. The model also uses the information on atmospheric column ozone amounts constituted from Total Ozone Mapping Spectrometer (TOMS) and NOAA TOVS archives, and the Stratospheric Monitoring Group's Ozone Blended Analysis (SMOBA), which is an assimilation product from the National Oceanic and Atmospheric Administration (NOAA) Climate Prediction Center. The release-3.0 GEWEX-SRB products have updated meteorology inputs from GEOS-4 (replacing the GEOS-1 inputs used in earlier versions) and are available as daily averages with a spatial resolution of $1^{\circ}$ latitude globally and longitudinal resolution varying from $1^{\circ}$ in the tropics to $120^{\circ}$ near the poles.

Regional observations of $\mathrm{SW}_{\text {rad }}$ were also collected to validate the GEOS-4 and MERRA datasets. In situ $\mathrm{SW}_{\text {rad }}$ measurements are available from approximately 300 agricultural and weather stations in the continental United States from 2001 to 2002 (Zhao et al. 2006, Fig. 1b). MERRA and GEOS-4 show large $\mathrm{SW}_{\text {rad }}$ discrepancies in arid regions and high latitudes; therefore, additional in situ $\mathrm{SW}_{\mathrm{rad}}$ measurements in those regions were obtained from the global flux tower (FLUXNET) network (Baldocchi et al. 2001). Six northern tower sites $\left(>60^{\circ} \mathrm{N}\right)$ covering all or a portion of the period from 2000 to 2006 were selected, including one Alaska site (USIvo, Epstein et al. 2004), one Russian site, and four European sites (Suni et al. 2003). Three arid tower sites with annual precipitation less than $400 \mathrm{~mm}$ were chosen and were located in Israel (IL-Yat), Botswana (BWWal), and Arizona (USSRM, Scott et al. 2009), respectively.

\section{c. Soil moisture observations}

Surface soil moisture observations $(\leq 15 \mathrm{~cm})$ from 26 sites were obtained from the AmeriFlux (Baldocchi et al. 2001) and Boreal Ecosystem Research and Monitoring Sites (BERMS; Griffis et al. 2004) datasets to validate MERRA and AMSR-E soil moisture results. These sites are also being used for SMAP Level 4 carbon algorithm development and testing. Woody savannah (USSRM) and boreal forest (CA-OJP) site comparisons were presented to evaluate the different performances of MERRA and AMSR-E soil moisture series in 
different hydroclimatic regions. Additional evaluation of MERRA soil moisture accuracy using Soil Climate Analysis Network (SCAN) observations is available from Reichle et al. (2011).

\section{d. Ancillary elevation datasets}

The elevation data were used to correct the influence of elevation on surface air temperatures. The elevations of the WMO stations are provided by NCDC. The 25-km Equal-Area Scalable Earth Grid (EASE-Grid) elevation data were obtained from NSIDC, which were regridded from the Global Land One-km Base Elevation (GLOBE) dataset (Knowles 2001). The MERRA topography was derived from the surface geopotential grid. The GEOS-4 model topography was obtained by regridding the U.S. Geological Survey (USGS) global 30 arc-second digital elevation model of the world (GTOPO30).

\section{e. Data processing}

Our analysis focused on daily time series because most hydro-ecological models, including the planned SMAP Level 4 carbon algorithms, operate at a daily step. The evaluated datasets were available at different time periods and spatial resolutions (Table 1). Comparisons between the different datasets were conducted for periods when all datasets were available. Therefore, comparisons involving the GEOS-4 analysis extended from 2000 to 2006 and the comparison period was confined from 2003 to 2006 when AMSR-E retrievals were included. The GEOS-4 analysis before 2004 was reprocessed and provided by NASA for the MODIS operational gross primary productivity (GPP) algorithms (Zhao et al. 2006). A reference grid with the finest spatial resolution was chosen from the evaluated datasets, and the other datasets were reprojected and resampled into this consistent grid scale for the subsequent comparisons. For example, for the $\mathrm{SW}_{\mathrm{rad}}$ comparison, the GEOS-4 and GEWEX-SRB grids were regridded to the MERRA $\left(0.5^{\circ}\right)$ grid scale, while the 25-km EASE Grid is chosen as the reference grid when the AMSR-E datasets were included. An inverse distance weight (IDW) method was employed to perform the spatial interpolation between different grids (Ma et al. 2008):

$$
A_{j}=\sum_{i=1}^{i=n}\left[W_{i}\left(A_{i}+\Delta A_{i}\right)\right] / \sum_{i=1}^{i=n} W_{i} \text {, }
$$

where $j$ and $i$ represent the regridded and original grid cell, respectively, $A_{i}$ is the value of the original grid cell, and $W_{i}$ is the weight of each grid, which is a simple function of the inverse of the distance between input and output grid cells (Zhao et al. 2005); $n$ is the number of input grid cells, and set as 4 in this study, and $\Delta A_{i}$ is used to correct for elevation effects on air temperatures using the standard environmental lapse rate (i.e., $6.0 \times$ $10^{-3}{ }^{\circ} \mathrm{C} \mathrm{m}^{-1}$ ). For VPD, the difference between actual vapor pressures at different altitudes was ignored, and only the elevation effect on daily averaged temperature (thus on saturated vapor pressure) was corrected.

For the comparison against in situ observations, all of the overlying grids were interpolated into a $25-\mathrm{km}$ EASE grid scale, and the grid cell closest to the sites was extracted. When comparing against the WMO stations, the elevation difference between the center of the extracted grid cell and WMO site was calculated and its influence on $T_{\min }, T_{\max }$, and VPD was corrected using the same method as above. Sites differing by more than $500 \mathrm{~m}$ from that of the gridcell average were dropped from the analysis to reduce pixel-point scale uncertainties.

Correlation coefficients $(R)$, bias, and RMSD were used as major performance metrics to evaluate the accuracy of MERRA surface meteorology (including $T_{\max }, T_{\text {min }}, \mathrm{VPD}$, and $\mathrm{SW}$ rad $)$. The correlation coefficient is used to assess the temporal correspondence between different datasets. The bias evaluates the difference between the means of different datasets and observations, and RMSD is a common measurement of the error (or difference) between the datasets incorporating both the variance and bias. The spatial distribution of uncertainty in MERRA/GEOS-4 and AMSR-E daily surface meteorology was assessed by examining latitudinal distributions of mean bias and RMSD against the in situ observations.

Generally, different soil moisture datasets show different statistical moments and are not directly comparable to each other in an absolute sense (Reichle et al. 2004). In addition, the soil moisture datasets used in this study have different units. The in situ observations and both AMSR-E datasets provide volumetric soil moisture (V\%) measurements, while MERRA data denote soil wetness (\%) defined as a proportion of soil saturation. Systematic bias between different datasets can be effectively removed by rescaling the datasets to a consistent mean and standard deviation (Reichle and Koster 2004; Koster et al. 2009; Draper et al. 2009). In this study, the biases between different soil moisture datasets were removed following Koster et al. (2009) before direct comparison. When the in situ data were available, the MERRA and AMSR-E soil moisture values were scaled to match the mean values and standard deviations of the observations. Otherwise, the AMSR-E soil moisture was normalized to match the statistics of the MERRA data. 
Correlations between MERRA and the two AMSR-E (VU and UM) daily soil moisture time series and their monthly means were used to evaluate global consistency in soil moisture variability among the three products. Grid cells with less than 30 daily soil moisture retrievals per year were excluded from the analysis. Correlations were calculated from the same pixels on a daily basis for both AMSR-E datasets. When there were more than 5 daily AMSR-E soil moisture retrievals per month, the AMSR-E and MERRA monthly means were calculated from the same available dates. Otherwise, only the MERRA monthly means were calculated. The correlations between MERRA-AMSR-E daily surface soil moisture and the AmeriFlux observations were summarized by global land cover class (DeFries et al. 1998) to evaluate the influence of vegetation type on modeled or satellite retrieved soil moisture. The soil moisture correlations were computed from in situ measurement series for sites exceeding a minimum threshold of 100 days of record using consistent dates and periods among the different data products. The approximate 95\% confidence intervals (CIs) of the correlations were also calculated. The CIs for a single site were based on the Fisher $Z$ transform, and the CIs for multiple sites were approximated by the division of the site-average CIs and the square root of the number of sites.

\section{REFERENCES}

Baldocchi, D., and Coauthors, 2001: FLUXNET: A new tool to study the temporal and spatial variability of ecosystem-scale carbon dioxide, water vapor, and energy flux densities. Bull. Amer. Meteor. Soc., 82, 2415-2434.

Berg, A. A., J. S. Famiglietti, J. P. Walker, and P. R. Houser, 2003: Impact of bias correction to reanalysis products on simulations of North American soil moisture and hydrological fluxes. J. Geophys. Res., 108, 4490, doi:10.1029/2002JD003334.

Betts, A. K., J. H. Ball, M. Bosilovich, P. Viterbo, Y. Zhang, and W. B. Rossow, 2003: Intercomparison of water and energy budgets for five Mississippi subbasins between ECMWF reanalysis (ERA-40) and NASA Data Assimilation Office fvGCM for 1990-1999. J. Geophys. Res., 108, 8618, doi:10.1029/ 2002JD003127.

—, M. Zhao, P. A. Dirmeyer, and A. C. M. Beljaars, 2006: Comparison of ERA40 and NCEP/DOE near-surface data sets with other ISLSCP-II data sets. J. Geophys. Res., 111, D22S04, doi:10.1029/2006JD007174.

Bloom, S., and Coauthors, 2005: Documentation and validation of the Goddard Earth Observing System (GEOS) data assimilation system-Version 4. NASA GSFC Tech. Rep. Series on Global Modeling and Data Assimilation 104606, Vol. 26, $187 \mathrm{pp}$.

Bosilovich, M. G., J. Chen, F. R. Robertson, and R. F. Adler, 2008: Evaluation of global precipitation in reanalysis. J. Appl. Meteor. Climatol., 47, 2279-2299.

_ F. R. Robertson, and J. Chen, 2011: Global energy and water budgets in MERRA. J. Climate, in press.
Cherkauer, K. A., L. C. Bowling, and D. P. Lettenmaier, 2003: Variable infiltration capacity cold land process model updates. Global Planet. Change, 38, 151-159.

Churkina, G., S. W. Running, and A. L. Schloss, 1999: Comparing global models of terrestrial net primary productivity (NPP): The importance of water availability. Global Change Biol., 5, $46-55$.

DeFries, R. S., M. C. Hansen, J. R. G. Townshend, and R. S. Sohlberg, 1998: Global land cover classifications at $8-\mathrm{km}$ spatial resolution: The use of training data derived from Landsat imagery in decision tree classifiers. Int. J. Remote Sens., 19, 3141-3168.

Dirmeyer, P. A., Z. Guo, and G. Xiang, 2004: Comparison, validation, and transferability of eight multiyear global soil wetness products. J. Hydrometeor., 5, 1011-1033.

Draper, C. S., J. P. Walker, P. J. Steinle, R. de Jeu, and T. Holmes, 2009: An evaluation of AMSR-E derived soil moisture over Australia. Remote Sens. Environ., 113, 703-710.

Entekhabi, D., and Coauthors, 2010: The Soil Moisture Active Passive (SMAP) mission. Proc. IEEE, 98, 704-716.

Epstein, H. E., M. P. Calef, M. D. Walker, F. S. Chapin, and A. M. Starfield, 2004: Detecting changes in arctic tundra plant communities in response to warming over decadal time scales. Global Change Biol., 10, 1325-1334.

Griffis, T. J., T. A. Black, D. Gaumont-Guay, G. B. Drewitt, Z. Nesic, A. G. Barr, K. Morgenstern, and N. Kljun, 2004: Seasonal variation and partitioning of ecosystem respiration in a southern boreal aspen forest. Agric. For. Meteor., 125, 207-223.

Jolly, W., R. R. Nemani, and S. W. Runnning, 2005: A generalized, bioclimatic index to predict foliar phenology in response to climate. Global Change Biol., 11, 619-632.

Jones, L. A., J. S. Kimball, K. C. McDonald, S. K. Chan, E. G. Njoku, and W. C. Oechel, 2007: Satellite microwave remote sensing of boreal and Arctic soil temperatures from AMSR-E. IEEE Trans. Geosci. Remote Sens., 45, 20042018.

, - E. Podest, K. C. McDonald, S. K. Chan, and E. G. Njoku, 2009: A method for deriving land surface moisture, vegetation, and open water fraction from AMSRE. Proc. IEEE Int. Geosci. Remote Sensing Symp. IGARSS '09, Cape Town, South Africa, IEEE, 916-919, doi:10.1109/IGARSS.2009.5417921.

-, C. R. Ferguson, J. S. Kimball, K. Zhang, S. K. Chan, K. C. McDonald, E. G. Njoku, and E. F. Wood, 2010: Satellite microwave remote sensing of daily land surface air temperature minima and maxima from AMSR-E. IEEE J. Sel. Top. Appl. Earth Obs. Remote Sens., 3, 111-123.

Kimball, J. S., S. W. Running, and R. R. Nemani, 1997: An improved method for estimating surface humidity from daily minimum temperature. Agric. For. Meteor., 85, 87-98.

- L. A. Jones, K. Zhang, F. A. Heinsch, K. C. McDonald, and W. C. Oechel, 2009: A satellite approach to estimate landatmosphere $\mathrm{CO}_{2}$ exchange for boreal and arctic biomes using MODIS and AMSR-E. IEEE Trans. Geosci. Remote Sens., 47, 569-587.

Knowles, K., cited 2001: EASE-Grid elevation data resampled from the Global Land One-km Base Elevation (GLOBE) project. National Snow and Ice Data Center. [Available online at http:// www.ngdc.noaa.gov/mgg/topo/report/globedocumentationmanual. pdf.]

Koster, R. D., M. J. Suárez, A. Ducharne, M. Stieglitz, and P. Kumar, 2000: A catchment-based approach to modeling land surface processes in a GCM. Part 1: Model structure. J. Geophys. Res., 105, 24 809-24 822. 
_, Z. Guo, R. Yang, P. A. Dirmeyer, K. Mitchell, and M. J. Puma, 2009: On the nature of soil moisture in land surface models. J. Climate, 22, 4322-4335.

Li, H., A. Robock, S. Liu, X. Mo, and P. Viterbo, 2005: Evaluation of reanalysis soil moisture simulation using updated Chinese soil moisture observations. J. Hydrometeor., 6, 180-193.

Ma, L., T. Zhang, Q. Li, O. W. Frauenfeld, and D. Qin, 2008 . Evaluation of ERA-40, NCEP-1, and NCEP-2 reanalysis air temperatures with ground-based temperatures in China. J. Geophys. Res., 113, D15115, doi:10.1029/2007JD009549.

$\mathrm{Mu}$, Q., L. A. Jones, J. S. Kimball, K. C. McDonald, and S. W. Running, 2009: Satellite assessment of land surface evapotranspiration for the pan-Arctic domain. Water Resour. Res., 45, W09420, doi:10.1029/2008WR007189.

Njoku, E. G., T. J. Jackson, V. Lakshmi, T. K. Chan, and S. N. Nghiem, 2003: Soil moisture retrieval from AMSR-E. IEEE Trans. Geosci. Remote Sens., 41, 215-229.

—, P. Ashcroft, T. K. Chan, and L. Li, 2005: Global survey and statistics of radio-frequency interference in AMSR-E land observations. IEEE Trans. Geosci. Remote Sens., 43, 938-947.

Owe, M., R. De Jeu, and J. P. Walker, 2001: A methodology for surface soil moisture and vegetation optical depth retrieval using the microwave polarization difference index. IEEE Trans. Geosci. Remote Sens., 39, 1643-1654.

- _- and T. Holmes, 2008: Multisensor historical climatology of satellite-derived global land surface moisture. J. Geophys. Res., 113, F01002, doi:10.1029/2007JF000769.

Pinker, R. T., and I. Laszlo, 1992: Modeling surface solar irradiance for satellite applications on a global scale.J. Appl. Meteor., 31, 194-211.

Randerson, J. T., and Coauthors, 2009: Systematic assessment of terrestrial biogeochemistry in coupled climate-carbon models. Global Change Biol., 15, 2462-2484.

Reichle, R. H., and R. D. Koster, 2004: Bias reduction in short records of satellite soil moisture. Geophys. Res. Lett., 31, L19501, doi:10.1029/2004GL020938.

— — - J. Dong, and A. A. Berg, 2004: Global soil moisture from satellite observations, land surface models, and ground data: Implications for data assimilation. J. Hydrometeor., 5 , 430-442.

- , and Coauthors, 2011: Assessment and enhancement of MERRA land surface hydrology estimates. J. Climate, in press.

Rienecker, M. M., and Coauthors, 2008: The GEOS-5 data assimilation system-Documentation of versions 5.0.1 and 5.1.0.
NASA GSFC Tech. Rep. Series on Global Modeling and Data Assimilation NASA/TM-2007-104606, Vol. 27, 95 pp.

Running, S. W., R. R. Nemani, F. A. Heinsch, M. Zhao, M. Reeves, and H. Hashimoto, 2004: A continuous satellite-derived measure of global terrestrial primary production. Bioscience, 54, 547-560.

Scipal, K., T. Holmes, R. de Jeu, V. Naeimi, and W. Wagner, 2008: A possible solution for the problem of estimating the error structure of global soil moisture data sets. Geophys. Res. Lett., 35, L24403, doi:10.1029/2008GL035599.

Scott, R. L., G. D. Jenerette, D. L. Potts, and T. E. Huxman, 2009: Effects of seasonal drought on net carbon dioxide exchange from a woody-plant-encroached semiarid grassland. J. Geophys. Res., 114, G04004, doi:10.1029/2008JG000900.

Sheffield, J., G. Goteti, and E. F. Wood, 2006: Development of a 50-yr high-resolution global dataset of meteorological forcings for land surface modeling. I. Climate, 19, 3088-3111.

Stieglitz, M., A. Ducharne, R. Koster, and M. Suarez, 2001: The impact of detailed snow physics on the simulation of snow cover and subsurface thermodynamics at continental scales. J. Hydrometeor., 2, 228-242.

Suni, T., and Coauthors, 2003: Long-term measurements of surface fluxes above a Scots pine forest in Hyytiälä, southern Finland, 1996-2001. Boreal Environ. Res., 8, 287-301.

Takala, M., J. Pulliainen, S. J. Metsamaki, and J. T. Koskinen, 2009: Detection of snowmelt using spaceborne microwave radiometer data in Eurasia from 1979 to 2007. IEEE Trans. Geosci. Remote Sens., 47, 2996-3007.

Yang, K., R. T. Pinker, Y. Ma, T. Koike, M. M. Wonsick, S. J. Cox, Y. Zhang, and P. Stackhouse, 2008: Evaluation of satellite estimates of downward shortwave radiation over the $\mathrm{Ti}$ betan Plateau. J. Geophys. Res., 113, D17204, doi:10.1029/ 2007JD009736.

Zhang, K., J. S. Kimball, Q. Mu, L. A. Jones, S. J. Goetz, and S. W. Running, 2009: Satellite based analysis of northern ET trends and associated changes in the regional water balance from 1983 to 2005. J. Hydrol., 379, 92-110.

Zhao, M., F. A. Heinsch, R. R. Nemani, and S. W. Running, 2005: Improvements of the MODIS terrestrial gross and net primary production global data set. Remote Sens. Environ., 95, 164-176.

—, S. W. Running, and R. R. Nemani, 2006: Sensitivity of Moderate Resolution Imaging Spectroradiometer (MODIS) terrestrial primary production to the accuracy of meteorological reanalysis. J. Geophys. Res., 111, G01002, doi:10.1029/ 2004JG000004. 